\title{
The AGP-PPAR $\gamma$ axis promotes oxidative stress and diabetic endothelial cell dysfunction
}

$$
\text { Ryoko Tsukahara }^{1} \text {, Hisao Haniu }{ }^{2}, \text { Yoshikazu Matsuda }^{3} \text { and Tamotsu Tsukahara }{ }^{1 *}
$$

\footnotetext{
${ }^{1}$ Department of Pharmacology and Therapeutic Innovation, Nagasaki University Graduate School of
} Biomedical Sciences, 1-14 Bunkyo-machi, Nagasaki 852-8521, Japan

${ }^{2}$ Institute for Biomedical Sciences, Shinshu University Interdisciplinary Cluster for Cutting Edge

Research 3-1-1 Asahi, Matsumoto, Nagano 390-8621, Japan

${ }^{3}$ Clinical Pharmacology Educational Center, Nihon Pharmaceutical University, Ina-machi, Saitama 362-0806, Japan

Running title: Role of AGP in eNOS regulation

*To whom correspondence should be addressed: Tamotsu Tsukahara, ${ }^{1}$ Department of Pharmacology and Therapeutic Innovation, Nagasaki University Graduate School of Biomedical Sciences, 1-14

Bunkyo-machi, Nagasaki 852-8521, Japan

E-mail: ttamotsu@nagasaki-u.ac.jp

Keywords: Diabetes; eNOS; NO; AGP; PPAR $\gamma$ 


\begin{abstract}
We previously showed that an alkyl-ether analog of lysophosphatidic acid, AGP accumulates in the atherogenic oxidized-LDL (ox-LDL) and human atherosclerotic plaques, and is a potent agonist of peroxisome proliferator-activated receptor-gamma (PPAR $\gamma)$. Recent studies have suggested a potential regulatory role of PPAR $\gamma$ on endothelial nitric oxide synthase (eNOS) expression and activation and NO generation in the vascular endothelium. Although nitrogen oxide (NO) derived from eNOS is known to be a vasodilator and exert vasoprotective effects, the excess NO production via NOS mediated cytotoxicity, including oxidative stress and apoptosis. Importantly, eNOS-induced NO and advanced glycation end products (AGEs) are involved in the damage sustained by blood vessels and induced apoptosis. Patients with diabetes have high levels of NO and AGEs in their blood; however, the effect of AGP on NO- and AGE-mediated dysfunction of the endothelium in these patients remains unknown. Therefore, we investigated such effect of AGP on NO- and AGE-mediated dysfunction using human coronary artery endothelial cells from donors with type 2 diabetes (D-HCAECs) and determined the underlying molecular mechanisms. Our results indicated that AGP upregulates eNOS expression and NO production in D-HCAECs. eNOS silencing by siRNA and an antagonist of PPAR $\gamma$ inhibited AGP-mediated eNOS upregulation and NO production. Notably, the AGP-PPAR $\gamma$ axis-mediated excess NO production promoted ROS generation and AGE formation in D-HCAECs. Furthermore, AGP induced LOX-1 and CD36 expression and therefore the uptake of ox-LDL into the subendothelial vasculature. The present data provide evidence that AGP has significant roles in the initiation and progression of diabetes-related atherosclerosis through the activation of PPAR $\gamma$.
\end{abstract}




\section{INTRODUCTION}

Atherosclerotic cardiovascular disease remains the leading cause of death in the industrialized world.

It is well known that the endothelium plays an important role in vascular disease, stroke, heart disease, and diabetes (1). In particular, diabetes has been reported to increases the risk of cardiovascular disease by accelerating the formation of atherosclerosis (2). The advanced glycation end products (AGEs) are involved in the damage of blood vessels and these products are high in diabetes patients. In addition, levels of oxidized low density protein (ox-LDL) and AGEs modified LDL in circulating bloods, and this event is strongly associated with increased levels of carotid intima-media thickness (3) (4). Endothelial cells act as barriers against thrombosis within plaques (5). Therefore, atherosclerotic lesions may be responsible for the stable-to-vulnerable plaque transition (6). A recent study reported that serum derived from patients with coronary syndrome induced apoptosis in endothelial cells, suggesting a correlation between apoptosis and complex coronary lesions (7). Besides its ability to promote inflammation in the atherosclerotic plaque, oxidized low-density lipoprotein (ox-LDL) also induces endothelial cell inflammation and apoptosis (8). Atherosclerosis is a chronic inflammatory process in the intima of conduit arteries, which disturbs the endothelium-dependent regulation of the vascular tone by NO formed by the constitutive endothelial nitric oxide synthase (eNOS). eNOS has been implicated in many human diseases associated with inflammation (9). Impaired cardiovascular function in type 2 diabetes mellitus is partially attributed to pathological overexpression of eNOS in the cardiovascular tissue (10). Since the insulin signaling pathway is coupled with eNOS activation, insulin resistance is associated with impaired nitric oxide (NO) bioavailability (11). Although NO derived from eNOS is known to be a vasodilator and has vasoprotecitve effects, excess NO plays an important role in the modulation of vascular cell apoptosis (12). Endothelial cell apoptosis is a physiological process that removes damaged cells from the vessel wall; excess NO induces apoptosis (13). Furthermore, increased formation of AGE is generally regarded as one of the main mechanisms responsible for vascular damage in patients with diabetes (14). We previously reported that alkyl-ether analog of lysophosphatidic acid, (AGP) accumulates in the atherogenic oxidized-LDL and human atherosclerotic plaques (15) (16), and is a potent agonist of peroxisome proliferator-activated receptor-gamma (PPAR $\gamma$ ) (17). AGP, but not acyl-LPA, is more 
Role of AGP in eNOS regulation

potently activates PPAR $\gamma$-mediated transcription compared to acyl-LPA, binding studies showed that binding of radiolabeled AGP was concentration dependent and saturable with an apparent of $60 \mathrm{nM}$ (17). However, whether AGP-PPAR $\gamma$ axis is involved in endothelial dysfunction induced by NO and AGE remains unknown. Here, we investigated the effect of AGP on NO and AGE production and endothelial dysfunction using primary human coronary artery endothelial cells (HCAECs) from donors with type II diabetes (D-HCAECs) and determined its underlying molecular mechanisms.

\section{MATERIALS AND METHODS}

\section{Materials}

AGP (18:1) was purchased from Avanti Polar Lipids, Inc. (Ann Arbor, MI, USA). We obtained 2ccPA (16:1) as a gift from Dr. Kimiko Murakami-Murofushi (Ochanomizu University, Tokyo, Japan). Mitochondrial uncoupler CCCP (carbonyl cyanide m-chlorophenylhydrazone) was purchased from Wako Pure Chemical (Tokyo, Japan). L-NAME ( $\mathrm{N}^{\mathrm{G}}$-Nitro-L-arginine methyl ester, hydrochloride) was purchased from Dojindo (Kumamoto, Japan). Ox-LDL, nLDL, and DiI-ox-LDL were obtained from Thermo Fisher Scientific (Yokohama, Japan). Antibodies against PPAR $\gamma$ (sc-7273) and $\beta$-actin (sc-47778) were purchased from Santa Cruz Biotechnology (Santa Cruz, CA, USA). Anti-eNOS antibody (3426R-30T) was purchased from Bio Vision (Milpitas, CA, USA). Hoechst 33342 was purchased from Dojindo (Kumamoto, Japan).

\section{Cell culture}

Primary human coronary artery endothelial cells (HCAECs) and HCAECs from donors with type II diabetes (D-HCAECs) were purchased from Lonza (Walkersville, MD, USA) and propagated in endothelial cell growth medium (EBM ${ }^{\mathrm{TM}}-2$, Lonza) containing $5 \%$ fetal bovine serum (FBS) and manufacturer-recommended supplemental growth factors $\left(\mathrm{EGM}-2^{\mathrm{TM}}\right.$ Bullekit $\left.^{\mathrm{TM}}\right)$, antibiotics, and antimycotics. All assays were performed on cells between passages 3 and 12. Characterization of the patients with Type 2 diabetes is provided from Lonza.com. 


\section{Small interfering RNAs}

We suppressed eNOS expression in HCAECs and D-HCAECs by transfecting the cells with small interfering RNAs (siRNAs) targeting eNOS (Santa Cruz Biotechnology, Santa Cruz, CA, USA). Lipofectamine RNAiMAX (Invitrogen, Carlsbad, CA, USA) was used for transfection. Cells were plated in 24-well plates (Iwaki, Tokyo, Japan) at a density of $5 \times 10^{4}$ cells/well in DMEM containing $10 \%$ FBS and then transfected with $100 \mathrm{pmol} / \mathrm{ml}$ of mRNA-specific siRNAs or scrambled siRNAs (control). Reduction of eNOS levels was confirmed by western blotting.

\section{Cell treatment}

HCAECs and D-HCAECs were plated in 12-well plates $\left(2 \times 10^{4}\right.$ cells/well $)$, and the medium was replaced the next day with DMEM/Ham's F-12 medium containing $2.5 \%$ charcoal-stripped FBS and either vehicle (dimethyl sulfoxide; DMSO) or AGP dissolved in DMSO. Fresh medium and AGP-containing medium were replaced every $48 \mathrm{~h}$. Each experiment was performed in triplicate, and results are expressed as means \pm standard error of mean (SEM) for each determination.

\section{Apoptosis assay}

The cells $\left(1 \times 10^{6}\right)$ were harvested and washed twice with ice-cold PBS. Subsequently, the cells were labeled with Annexin V \& Dead Cell Assay kit according to the manufacturer's instructions (Merck Millipore, Darmstadt, Germany). This assay is based on the detection of phosphatidylserine (PS) on the apoptotic cells surface using fluorescently labeled Annexin V in combination with the dead cell marker, 7-Aminoactinomycin D (7-AAD). The samples were counted by using the Muse Cell Analyzer (Merck Millipore) and analyzed using a software provided by Merck Millipore.

\section{Quantitative real-time PCR analysis}

Total RNA was isolated from cells by using a NucleoSpin ${ }^{\circledR}$ RNA II kit (TAKARA, Shiga, Japan), and $0.5 \mu \mathrm{g}$ of the RNA was used for the subsequent synthesis of cDNA by using a ReverTra Ace qPCR RT kit (Toyobo, Osaka, Japan) per manufacturer's instructions. The mRNA levels were measured by using an ECO real-time PCR system (Illumina, Inc., San Diego, CA, USA) and SYBR Green 
Real-Time PCR Master Mix -Plus- (Toyobo) with the primer pairs listed in supplementary Table 1. All PCRs were performed in $10 \mu \mathrm{L}$ mixtures in 48-well PCR plates (Illumina). The cycling condition was as follows: $95^{\circ} \mathrm{C}$ for $10 \mathrm{~min}$ (polymerase activation), followed by 40 cycles of $95^{\circ} \mathrm{C}$ for $15 \mathrm{~s}$, $55^{\circ} \mathrm{C}$ for $15 \mathrm{~s}$, and $72^{\circ} \mathrm{C}$ for $30 \mathrm{~s}$. After amplification, the samples were slowly heated from $55^{\circ} \mathrm{C}$ to $95^{\circ} \mathrm{C}$ and fluorescence was measured continuously to obtain a melting curve. The relative mRNA levels were quantified by using the formula $2^{-\Delta \Delta \mathrm{Ct}}$, where $\Delta \mathrm{Ct}$ is the difference between the threshold cycle of a given target cDNA and an endogenous reference cDNA.

\section{Western blot}

The proteins were separated on 5-20\% sodium dodecyl sulfate (SDS)-polyacrylamide (SDS-PAGE) gels (e-PAGEL; ATTO, Tokyo, Japan) and electrotransferred to Immobilon-P membranes (Merck Millipore). The membranes were blocked in Block Ace (DS Parma Biomedical Co. Ltd., Osaka, Japan) for $1 \mathrm{~h}$ and then incubated with a primary antibody in Tris-buffered saline-Tween 20 with 5\% Block Ace for $12 \mathrm{~h}$ at $4^{\circ} \mathrm{C}$. After a wash is conducted to remove unbound primary antibody followed by the incubation with horseradish peroxidase (HRP) conjugated secondary antibody. Bands were visualized with EzWestLumi plus (ATTO, Tokyo, Japan). Regarding the isolation of cytoplasmic and nuclear proteins, NE-PER nuclear and cytoplasmic extraction reagents (Pierce, Rockford, IL, USA) were used and western blot was performed as described above.

\section{Immunofluorescence confocal microscopy}

The immunofluorescence assay for PPAR $\gamma$ nuclear translocation was performed according to the previous method (18). Briefly, cells were fixed with $3.7 \%$ formaldehyde in PBS for $30 \mathrm{~min}$ and incubated with anti-PPAR $\gamma$ antibody $(1: 100)$ for $1 \mathrm{~h}$ at room temperature following the staining with Alexa Fluor 488-conjugated anti-mouse IgG (1:2000) (Life technology, CA, USA) and Hoechst 33342 (Dojindo, Kumamoto, Japan) for 2 h. Fluorescent images were acquired using a fluorescence microscope (model BZ-X700; Keyence, Osaka, Japan). 
The level of nitrates was assayed in the samples using a nitric oxide assay kit (AB65328, Abcam, Cambridge, MA, USA) at $540 \mathrm{~nm}$ in a colorimetric microplate reader ChroMate ${ }^{\circledR}$ microplate reader (Awareness Technology, Palm City, FL, USA). In brief, cells $\left(1 \times 10^{6}\right)$ were treatment with or without AGP for the indicated time points, then harvested and washed the cells with cold PBS. Resuspended and homogenized cells in $100 \mu \mathrm{L}$ of ice cold assay buffer, centrifuge cell for $3 \mathrm{~min}$ at $4^{\circ} \mathrm{C}$ at $13,000 \times \mathrm{g}$. Added ice cold $4 \mathrm{M}$ perchloric acid $(\mathrm{PCA})$ to a final concentration of $1 \mathrm{M}$ in the homogenate solution, then centrifuged samples at $13,000 \times \mathrm{g}$ for $2 \mathrm{~min}$ at $4^{\circ} \mathrm{C}$. Precipitated excess PCA by adding an equal volume of cold $2 \mathrm{M} \mathrm{KOH}$ to supernatant (adjust $\mathrm{pH}$ to 6.5-8). Centrifuge at $13,000 \times \mathrm{g}$ for $15 \mathrm{~min}$ at $4^{\circ} \mathrm{C}$ and the supernatant was used in the assay.

\section{Measurement of PPAR $\gamma$ activity}

To determine PPAR $\gamma$ activation, cells were co-transfected with the pGL3b-PPRE-Luc and pSV40- $\beta$-galactosidase reporter plasmids and analyzed by using a luciferase reporter assay, as previously described (17) (18) (19).

\section{ROS production}

Cells were seeded in 24-well plates at a density of $5 \times 10^{4}$ cells/well and incubated at $37^{\circ} \mathrm{C}$ for $24 \mathrm{~h}$. Then, the culture medium was aspirated and cells were washed with Dulbecco PBS (DPBS) followed by the addition of $1 \mathrm{ml}$ of fresh culture medium containing either DMSO or $10 \mu \mathrm{M}$ carboxy-DCFDA (C-400, Molecular Probes, CA, USA). After incubation for $15 \mathrm{~min}, 10 \mu \mathrm{L}$ of DMSO or $10 \mu \mathrm{M}$ carboxy-DCFDA was added to the cells. Hydrogen peroxide $(100 \mu \mathrm{M})$ was used as a positive control stimulus. Following incubation for $60 \mathrm{~min}$, the cells were washed by DPBS and harvested with trypsin-EDTA. Finally, the cells were suspended with $0.3 \mathrm{~mL}$ of $10 \%$ FBS in DPBS and passed through nylon mesh. Cells were subjected to flow cytometry (FACSCalibur ${ }^{\mathrm{TM}}$, Becton-Dickinson, San Jose, CA, USA) until 20,000 events were recorded. 
AGE concentrations were determined using the OxiSelect ${ }^{\mathrm{TM}}$ Advanced Glycation End Product (AGE) ELISA kit (Cell Biolabs, Inc. San Diego, CA) following manufacturer's instruction. Cells were seeded in 96-well plates at a density of $1 \times 10^{4}$ cells/well and incubated at $37^{\circ} \mathrm{C}$ for $24 \mathrm{~h}$. The cells were incubated with $10 \mu \mathrm{M}$ AGP with or without GW9662 for $72 \mathrm{~h}$, then AGE were detected using an anti-AGE antibody (1:1000) with HRP-conjugated secondary antibody (1:1000) and detected spectrophotometrically at $450 \mathrm{~nm}$. Absorbances were measured by colorimetric microplate reader ChroMate ${ }^{\circledR}$ Microplate Reader (Awareness Technology, Palm City, FL, USA).

\section{Mitochondrial membrane potential}

The mitochondrial membrane potential changes were determined using the Muse Cell Analyzer (Merck Millipore, Darmstadt, Germany) and the Muse MitoPotential kit (Merck Millipore, Darmstadt, Germany) according to the manufacturer's instructions. Briefly, cells grown in 12-well plates were treated with DMSO (vehicle) or $10 \mu \mathrm{M}$ AGP for $24 \mathrm{~h}$, collected by trypsinization, washed by PBS, and incubated with the Muse Mitopotential dye, a cationic lipophilic dye, for $20 \mathrm{~min}$ at $37^{\circ} \mathrm{C}$. Cells were then incubated with 7-AAD, a dead cell marker, for $5 \mathrm{~min}$ at room temperature.

\section{Uptake of DiI-ox-LDL in D-HCAECs}

D-HCAECs were cultured on a glass-bottom culture dish (Matsunami Glass, Tokyo, Japan). The cells were incubated with $10 \mu \mathrm{M}$ AGP for $24 \mathrm{~h}$, and then 5 or $50 \mu \mathrm{g} / \mathrm{mL}$ DiI-ox-LDL (a fluorescent ox-LDL) was added to the medium containing control antibody (normal mouse IgG, sc-2025, SCBT) or anti-LOX-1 antibody (MAB1798-SP, R\&D Systems, Minneapolis, MN, USA) and incubation was continued for $2 \mathrm{~h}$. The cells were fixed with $4 \%$ formaldehyde and $0.2 \%$ glutaraldehyde in PBS and examined by fluorescence microscopy.

\section{Animals and treatment}

Animal experiments were performed in collaboration with Unitech Co. Ltd. (Chiba, Japan). BALB/c KOR/SteSlc-Apoeshl mice (6-weeks-old), weighing 20-25 g were purchased from Japan SLC, Inc. (Shizuoka, Japan). The animals were maintained in a humidity-controlled room on a 12-h light-dark 
cycle with standard food and water available ad libitum for 1 week. The mice were then divided randomly into two groups, with four animals in each group, and fed high-fat diet (D12108C, 1.25\% cholesterol) purchased from Research Diet Inc. (New Brunswick, NJ, USA) for 4 weeks. The ApoE-/ + 2ccPA group was administered 2ccPA (16:1) $(5 \mathrm{~mL} / \mathrm{kg}$ bodyweight, $2 \mathrm{mg} / \mathrm{mL}$ in phosphate-buffered saline $[\mathrm{PBS}]$ ) by intraperitoneal injection, while the control group (ApoE-/group) was administered an equal volume of PBS for 4 weeks. The carotid arteries of the mice were harvested 14 days after initiation of the high fat diet in collaboration with Unitech and total RNA was extracted using TRIzol reagent (Life Technologies, Carlsbad, CA, USA). Whole lipids were extracted using the Bligh and Dyer method as described previously (18). The extracted lipids were dissolved in $0.1 \mathrm{~mL}$ methanol/chloroform/28\% $\mathrm{NH}_{4} \mathrm{OH}$ (90:10:0.1), and immediately analyzed by electrospray ionization-liquid chromatography-mass spectrometry (ESI-LC-MS). Liquid chromatography-mass spectrometry (LC-MS) was performed on an LCMS-2010A mass spectrometer (Shimadzu, Kyoto, Japan) equipped with a $50 \mathrm{~mm} \times 4.6 \mathrm{~mm}$ Econosphere $3 \mu \mathrm{m}$ silica column (Alltech Associates Inc.,

Deerfield, IL, USA). The sample was maintained at $250^{\circ} \mathrm{C}$ using a drying gas flow at $1.5 \mathrm{~L} / \mathrm{min}$, and data was collected in the negative ion mode from 100 to $1,000 \mathrm{~m} / \mathrm{z}$. AGP was quantified by comparing the $[\mathrm{M}-\mathrm{H}]^{-}$signal intensity of AGP to that of the internal standard AGP 17:0.

\section{Statistical analysis}

For statistical analysis, the data were analyzed by unpaired Student's t-test or one-way analysis of variance (ANOVA) followed by Dunnett's or Tukey's using GraphPad Prism (Graphpad Software Inc.). The results were expressed as the mean \pm SEM.

\section{RESULTS}

\section{Expression of cell adhesion molecules in HCAECs and D-HCAECs}

A variety of cell types, growth factors, cytokines, and vasoregulatory molecules participate in the pathogenesis of diabetes (20). It has been reported that cell adhesion molecules such as intercellular cell adhesion molecule-1 (ICAM-1) and vascular cell adhesion molecule-1 (VCAM-1), P-selectin, and E-selectin are highly expressed in atherosclerotic plaques in patients with diabetes (21) and these 
molecules are implicated in the initiation and development of diabetes. High glucose enhances endothelial neutrophil adhesion via expression of these adhesion molecules. To characterize the difference between two cell types, HCAECs and D-HCAECs, we first examined the mRNA expression levels of cell adhesion molecules, ICAM-1, VCAM-1, P-selectin. The mRNA levels of cell adhesion molecules were significantly higher in D-HCAECs than in HCAECs (Supplemental data Fig.1).

\section{Effect of AGP on eNOS expression in HCAECs and D-HCAECs}

We previously showed that alkyl-ether analog of LPA, AGP accumulates in the atherogenic ox-LDL and human atherosclerotic plaques (16). Diabetes-mediated atherosclerosis is a chronic inflammatory process in the intima of arteries, which disturbs the endothelium-dependent regulation of the vascular tone by NO formed by the constitutive endothelial nitric oxide synthase (eNOS) (22). We therefore investigated whether AGP had effect on the expression of eNOS and NO production in HCAECs and D-HCAECs. Cells were treated with AGP, and eNOS mRNA level was examined by real-time PCR analysis. As shown in Fig. 1A and 1B, AGP significantly increased eNOS mRNA level in a time- and dose- dependent manner in D-HCAECs. eNOS mRNA levels slightly increased in HCAECs but the extent of increase in D-HCAEC was higher than that in HCAECs. Next, the cells were stimulated with various concentrations of AGP for different periods and NO levels were determined as shown in Fig. 1C and 1D. AGP induced NO production in a dose- and time-dependent manner in D-HCAECs. A more prominent AGP-induced elevation of NO levels was observed during the first $3 \mathrm{~h}$ of treatment in D-HCAECs followed by a decrease in NO levels within $6 \mathrm{~h}$ of incubation. Furthermore, to determine whether the AGP-induced NO production depended on eNOS, D-HCAECs were treated with eNOS siRNA. As shown in Fig. 1E, real-time quantitative PCR analysis showed that eNOS mRNA expression in siRNA transfected cells was reduced by $80 \%$ compared to the expression in control siRNA-transfected cells. Western blot analysis using an anti-eNOS antibody showed that eNOS knockdown in D-HCAECs was effective (Fig. 1F). The induction of NO production by AGP was inhibited in eNOS siRNA transfected D-HCAECs (Fig. 1G). These results confirmed that AGP induced eNOS augmentation resulted in the increase of NO production in D-HCAECs. 


\section{AGP induced apoptosis in D-HCAECs, but not in HCAECs}

Another important study is that the level of apoptotic cell death is strongly related to the stage of development of the atherosclerotic plaque (23). Endothelial cells within the atherosclerotic plaque become programmed to die and those additional factors such as lipid-derived products were focally present in the plaque that terminated the cell death program (23). Several studies indicate that microvascular cell apoptosis plays an important role in the development of early lesions (24) (25). As shown in Fig. 2A, a cell that is undergoing apoptosis exhibits nuclear condensation and DNA fragmentation, which can be detected by staining with Hoechst 33342. The viability of AGP-treated D-HCAECs was reduced as early as at $48 \mathrm{~h}$ of treatment, as visualized by apoptotic nuclear morphology. However, when HCAECs were treated with AGP, less than $10 \%$ of apoptotic cells was observed. We evaluated the percentage of apoptotic D-HCAECs after treatment with 1,3 , and $10 \mu \mathrm{M}$ AGP by Annexin V staining and stained cells were detected by flow cytometry. As shown in Fig. 2B, treatment with AGP increased the ratio of apoptotic D-HCAECs in a concentration-dependent manner. Next, we investigated whether AGP induced changes in mitochondrial potential, an early hallmark of apoptosis (26). As shown in Fig. 2C, AGP induced an increase in the number of cells with depolarized mitochondrial membranes in D-HCAECs but not in HCAECs, suggesting that AGP causes depolarization of mitochondrial potential, which could be linked to the activation of apoptosis in D-HCAECs. Macrophage activation causes release of proinflammatory reactive oxygen species (ROS), cytokines, proteolytic enzymes involved in matrix degradation and subsequently atherosclerotic plaque destabilization (27). We next examined ROS production in AGP-treated HCAECs and D-HCAECs. As shown in Fig. 2D, Interestingly, ROS production in D-HCAECs was significantly increased upon treatment with AGP than in HCAECs. ROS levels influence the expression of key genes such as heme oxygenase-1 (HO-1) and glutathione synthetase (GSS) involved in regulating cellular and systemic oxidative stress (28). As shown in Fig. 2E, the HO-1 mRNA was expressed at higher levels in D-HCAECs than in HCAECs after treatment with AGP. Furthermore, loss of glutathione and oxidative damage has been suggested to constitute early 
signaling events in apoptotic cell death (29). GSS mRNA was expressed at lower levels in D-HCAECs than in HCAECs after treatment with AGP.

\section{AGP induced PPAR $\gamma$ expression and activation in D-HCAECs}

Our previous report suggests that AGP is a high affinity agonist of the peroxisome proliferator-activated receptor gamma (PPAR $\gamma$ ) (17). PPAR $\gamma$ ligands have antihypertensive effects related at least in part to their ability to promote peripheral vasodilation, improve insulin sensitivity, and decrease the risk for atherosclerosis (30). Humans express two PPAR $\gamma$ isoforms, PPAR $\gamma 1$ and PPAR 2 , originating from alternative splicing. We first examined the mRNA levels of PPAR 1 and PPAR 2 in HCAECs and D-HCAECs. As shown in Fig. 3A, the PPAR 1 mRNA was expressed at higher levels in D-HCAECs than in HCAECs. In contrast to PPAR 1 mRNA expression, PPAR 2 expression was low in the two types of primary human coronary endothelial cells. We next investigated PPAR $\gamma$ protein levels in the cells (Fig. 3A, right) and observed that HCAECs and D-HCAECs expressed distinct levels of PPAR $\gamma 1$. PPAR $\gamma 1$ and PPAR $\gamma 2$ protein expression levels were consistent with the mRNA levels in this study and corroborated the results of a previous study (19). To investigate the effects of AGP on PPAR 1 and PPAR 2 mRNA levels, D-HCAECs were treated with AGP $(10 \mu \mathrm{M})$, and their mRNA levels were examined using real-time PCR analysis. As shown in Fig. 3B, AGP only induced PPAR 1 mRNA expression as early as 24 h post-stimulation, which persisted until $72 \mathrm{~h}$ post-stimulation in D-HCAECs. Some reports show that in the presence of selective ligands, including AGP, PPAR $\gamma$ undergoes a conformational change, facilitating the dissociation of co-repressors and the recruitment of co-activators, which results in the transcriptional activation of target genes (18). Interestingly, pGL3-PPRE-acyl-CoA oxidase luciferase activity increased in D-HCAECs after exposure to AGP in a dose-dependent manner. Fig. 3C shows a PPRE reporter gene assay to determine the PPAR $\gamma$ transcriptional activation by luciferase measurement. The luciferase increased in D-HCAECs after exposure to AGP in a dose-dependent manner, and this activation was attenuated by PPAR $\gamma$ antagonist GW9662. As a positive control, luciferase expression from the PPRE identified in the acyl-CoA oxidase promoter (Acox-PPRE) was induced by rosiglitazone by 2.5 -fold. We also examined the expression level of PPAR $\gamma$-regulated genes, CD36, 
$F A B P 3, F A B P 4$, and $C Y P 27 A 1$, and found that these genes were up-regulated following AGP treatment in D-HCAECs (Supplemental data Fig. 2). This result is consistent with PPAR $\gamma$ expression level. It is known that PPAR $\gamma$ translocates from the cytosol to the nucleus upon activated (31) (32). The immunofluorescence assay against PPAR $\gamma$ showed that PPAR $\gamma$ nuclear translocation was observed after AGP treatment in D-HCAECs (Fig.3D \& 3E).

\section{AGP-mediated PPAR $\gamma$ activation increased both eNOS expression and NO production and apoptosis in D-HCAECs}

Recent study suggested a potential regulatory role of PPAR $\gamma$-dependent eNOS expression and NO generation in the vascular endothelium (33). As shown in Fig. 4A, AGP increased both eNOS expression and NO production in a dose-dependent manner in D-HCAECs and these effects were inhibited by GW9662, a selective and irreversible inhibitor of PPAR $\gamma$ suggesting that these effects eNOS and NO were through the activation of PPAR $\gamma$ by AGP. Recent evidence suggests that generation of excess nitric oxide due to various stimuli may play an essential role in the induction of apoptosis (13). As shown in Fig. 4B, to explore the involvement of NO in AGP-induced apoptosis, we used the NOS inhibitor L-NAME and analyzed AGP-induced apoptosis. AGP alone increased apoptotic cells, however, pretreatment of D-HCAECs with L-NAME inhibited AGP-induced apoptosis. These results suggest that AGP-induced apoptosis is mediated by NO. Furthermore, inhibition of insulin-induced glucose uptake caused by AGP was effectively reversed by GW9662 treatment in D-HCAECs but not in HCAECs. These results indicated that AGP inhibits insulin-induced intracellular glucose uptake via PPAR $\gamma$ activation (Fig. 4C). The AGP-PPAR $\gamma$ axis may play a role in the effect of glucose-mediated endothelial cell dysfunction. Excessive production of AGE also appears to be important in the pathogenesis of diabetic complications. We therefore investigated the effects of AGP on hyperglycemia-induced formation of intracellular methylglyoxal-derived AGE. The carbonyl cyanide m-chlorophenylhydrazone (CCCP), which is mitochondrial uncoupler reagent, prevented AGE production (Fig. 4D). In addition, induction in AGP-induced AGE production was effectively inhibited by GW9662 treatment. These results also suggested that formation of AGE appears to be enhanced in D-HCAECs via AGP-mediated PPAR $\gamma$ 
activation. Taken together, our results indicate that AGP mediated PPAR $\gamma$ activation induced eNOS expression and excess NO and AGE were also induced apoptosis in D-HCAECs.

\section{Oxidized LDL (ox-LDL) and AGP induced LOX-1 and CD36}

The generation of ox-LDL in the subendothelial vasculature is an early event during diabetes-mediated atherogenesis (34). The scavenger receptor lectin-like oxidized-low-density lipoprotein receptor-1 (LOX-1) and cluster of differentiation 36 (CD36) are responsible for binding and uptaking of ox-LDL in endothelial cells (35). We examined whether ox-LDL affected LOX-1 and CD36. As shown in Fig. 5A, ox-LDL but not normal LDL (nLDL) induced LOX-1 and CD36 expression in a concentration-dependent manner. We next examined the effect of AGP on $L O X-1$ and CD36 expression. AGP significantly increased $L O X-1$ and $C D 36$ mRNA levels, and this effect was attenuated by GW9662 (Fig. 5B). To investigate whether the effect of ox-LDL was involved in PPAR $\gamma$ activation, a PPAR $\gamma$ reporter gene assay was performed. Luciferase activity increased in D-HCAECs after exposure to ox-LDL in a concentration-dependent manner, and this effect was inhibited by GW9662 (Fig. 5C). These findings suggest that PPAR $\gamma$ signaling may play a role in atherogenesis induced by ox-LDL. Next, we determined whether the induction of LOX-1 by AGP was accompanied by ox-LDL uptake by D-HCAECs. Next, we determined whether the induction of LOX-1 by AGP was accompanied by ox-LDL uptake by D-HCAECs. The AGP-treated D-HCAECs showed intense fluorescence for Dil-ox-LDL and the enhanced the uptake was significantly hampered by the introduction of an anti-LOX-1 antibody (Fig. 5D). These results suggest that LOX-1 expression is associated with the AGP-PPAR $\gamma$ pathway, which leads to accelerate the progression of atherosclerosis. It has also been reported that LOX-1 expression was enhanced by diabetes-associated conditions including inflammation, hyperlipidemia, and hypertension (36). Therefore, we examined the effect on the expression of cytokines and chemokines. As shown in Fig. 5E, AGP increased the expression level of IL-6, MCP-1, and TNF- $\alpha$ in D-HCAECs. These results further confirmed the role of AGP in the induction of cytokines and chemokines in D-HCAECs.

High-fat diet induced AGP production in the carotid arteries was inhibited by 2ccPA 
Our previous study suggested that a high-fat diet stimulation in apolipoprotein E knockout (apoE-/-) mice elicits direct activation of PPAR $\gamma$-regulated genes, and that cyclic phosphatidic acid (cPA) and its analog 2ccPA completely abolished the transcriptional regulation of these genes (37). Moreover, cPA inhibits the progression of arterial wall thickness. cPA has been reported to inhibit PPAR $\gamma$, which is the opposite of the effect of AGP (18). High levels of AGP have also been observed in the lipid-rich necrotic core of human carotid artherosclerotic plaques (16). Here, AGP levels in the carotid arteries from 2ccPA treated mice were analyzed by LC-MS/MS. As shown in Fig.6A, the following individual fatty acid species were analyzed by LC-MS/MS: palmitic acid (16:0), stearic acid (18:0), and oleic acid (18:1). 2ccPA treated HFD ApoE-/- mice showed significantly decreased total AGP level and AGP species with unsaturated fatty acids, in particularly, AGP (18:1), showed a much greater decrease than other AGP species. Next, the short treatment durations were chosen to examine the early phases of atherogenesis to explore potential initiating mechanisms. 2ccPA treated HFD ApoE-/- mice showed significantly decreased total aortic atherosclerosis compared to HFD ApoE-/mice (Fig.6B). The carotid arteries of the mice were harvested 14 days after initiation of the high fat diet, and mRNA levels of the eNOS, LOX-1,CD36, and IL-6 genes were analyzed. As shown in Fig.6C, the expression level of these genes decreased in 2ccPA treated HFD ApoE-/- mice. A significant reduction of 2ccPA treatment influenced on the gene expression of eNOS, LOX-1, CD36, and IL-6 in the carotid artery, and this result is consistent with the effect of AGP in D-HCAECs. AGP 18:1 is more potent PPAR $\gamma$ agonist than unsaturated AGP such as 16:0 and 18:0 (17), therefore, these results imply that the decrease in the level of AGP18:1 by 2ccPA down-regulates eNOS and other targeted genes.

\section{DISCUSSION}

Coronary artery disease is the most morbid cardiovascular complication of diabetes mellitus with a two- to four-fold increased risk (38). Compared to cardiovascular disease in non-diabetics, diabetic patients have a greater overall coronary plaque burden and a higher rate of multivessel disease (39), however, the detailed mechanism behind AGP occurrence still remains unsolved. This study was performed to determine the relationship between the AGP and AGP-mediated intracellular signaling, 
because of AGP concentration is highly elevated in the lipid-rich core of human atherosclerotic plaques (16). Here, we focus in greater detail on the intracellular signaling is NO. The first reports on NO-induced apoptosis appeared in 1993 (40) (41). Since then, NO-induced apoptosis has been reported in different primary or immortalized cells (41) (42). Several studies suggest that a direct transcriptional mechanism may be involved in PPAR $\gamma$-mediated release of NO in endothelial cells. In this study, we identified that AGP increased eNOS expression and NO production through the activation of PPAR $\gamma$ in D-HCAECs but not in HCAECs. In atherosclerosis, exposure to AGP induced progressive neointima formation (16) (35) and, AGP was shown to stimulated a new type of signaling by directly activating PPAR $\gamma$ (17) (43). A previous report suggested that topical application of AGP on the non-injured carotid artery induced arterial-wall remodeling, and this response required PPAR $\gamma$ (16). AGP is an agonist of PPAR $\gamma$ and has been implicated in the involvement of atherogenesis (16) (17). Hyperglycemia is a key factor for the pathogenesis of diabetic microvascular complications (44). A high concentration of AGP in the circulatory system may be a risk factor for the development of atherosclerosis in diabetic patients. In addition, one of the key concepts for free radical mediated pathogenesis of cardiovascular disease is endothelial dysfunction, whereby the regulation of the vascular wall microenvironment is disrupted. ROS has been implicated in atherogenesis and plaque instability (45). Cellular damage to the cardiovascular system is mainly due to lipid peroxidation caused by the action of ROS on cellular lipids such as polyunsaturated fatty acids, phospholipids, LDL, and VLDL. In this study, we showed that AGP-mediated ROS production induced apoptosis in D-HCAECs and that this is involved in the effect of ox-LDL. Thus, these molecules can be used as biomarkers as they are associated with prognosis of diabetes-related atherogenesis. A previous report suggested that ox-LDL induced LPA-like biological activity (16). The biological properties of AGP are distinct from those of acyl-LPA. For example, AGP is 50-times more potent than acyl-LPA for platelet activation (16). AGP levels have been quantified in LDL preparations and AGP content is six-fold higher in ox-LDL, with the octadecenyl (18:1) species showing a 10-fold increase over nLDL (16). The rank order of AGP species present in ox-LDL was the same as that reported for the lipid core of human atherosclerotic plaques, where AGP is likely derived from ox-LDL (16). In this study, an oxidative stress marker, HO-1 was remarkably induced by AGP in D-HCAECs. However, GSS 
mRNA was expressed at lower levels in D-HCAECs than in HCAECs. These results suggest that AGP-induced ROS levels influenced the expression of HO-1 and GSS involved in regulating intracellular oxidative stress. Recent studies indicate that the effects of AGEs on vessel wall homeostasis may contribute to rapidly progressive atherosclerosis associated with diabetes mellitus (46). It has been reported that AGP concentration is highly elevated in the lipid-rich core of human atherosclerotic plaques, where AGP is likely derived from ox-LDL (16). In this manner, PPAR $\gamma$ modulation by AGP is a promising field of study because such modulation might cause dysfunction in diabetes-mediated atherosclerosis. Our current study also identified increased AGP levels in the carotid artery of apoE-/- mice. These results suggest that AGP in the circulatory system may be a risk factor for development of diabetes-mediated atherosclerosis. We identified that a significant increase of AGP influenced the atherosclerosis-related gene expression in the carotid artery. In conclusion, we discovered a link among AGP-mediated PPAR $\gamma$ activation, excess NO production, and oxidative stress in diabetic endothelial cells and diabetes model animal. Our results broaden the cardiovascular disease-related significance of excess NO. These findings offer a novel molecular mechanism underlying the diabetes-related atherogenesis mediated by excess $\mathrm{NO}$ and provide new insights into possible targets for therapeutic interventions in diabetes-related cardiovascular diseases. Taken together, these results suggested that the AGP-PPAR $\gamma$-eNOS axis is a significant contributor to endothelial dysfunction in D-HCAECs and further research with a clearer focus on the development of atherosclerosis-specific therapeutic targets is required

\section{ACKNOWLEDGMENTS}

This work was supported by grants from SENSHIN Medical Research Foundation (2-06 to Tamotsu Tsukahara).

\section{DISCLOSURE STATEMENT}

The authors have nothing to disclose.

\section{AUTHOR CONTRIBUTIONS}


Role of AGP in eNOS regulation

T.T. conceived and designed the project. T.T., R.T., S.Y., Y.M., and H.H. acquired the data. T.T. and H.H. analyzed and interpreted the data, and T.T. wrote the article. All authors have read and approved the final version of the article. 


\section{REFERENCES}

1. Ellulu, M. S., Patimah, I., Khaza'ai, H., Rahmat, A., Abed, Y., and Ali, F. (2016) Atherosclerotic cardiovascular disease: a review of initiators and protective factors. Inflammopharmacology $\mathbf{2 4 ,}$ $1-10$

2. Yahagi, K., Kolodgie, F. D., Lutter, C., Mori, H., Romero, M. E., Finn, A. V., and Virmani, R. (2017) Pathology of Human Coronary and Carotid Artery Atherosclerosis and Vascular Calcification in Diabetes Mellitus. Arterioscler Thromb Vasc Biol 37, 191-204

3. Lopes-Virella, M. F., Hunt, K. J., Baker, N. L., Lachin, J., Nathan, D. M., Virella, G., Diabetes, C., Complications Trial/Epidemiology of Diabetes, I., and Complications Research, G. (2011) Levels of oxidized LDL and advanced glycation end products-modified LDL in circulating immune complexes are strongly associated with increased levels of carotid intima-media thickness and its progression in type 1 diabetes. Diabetes 60, 582-589

4. Peppa, M., Brem, H., Ehrlich, P., Zhang, J. G., Cai, W., Li, Z., Croitoru, A., Thung, S., and Vlassara, H. (2003) Adverse effects of dietary glycotoxins on wound healing in genetically diabetic mice. Diabetes 52, 2805-2813

5. Yau, J. W., Teoh, H., and Verma, S. (2015) Endothelial cell control of thrombosis. BMC Cardiovasc Disord 15, 130

6. Negre-Salvayre, A., Auge, N., Camare, C., Bacchetti, T., Ferretti, G., and Salvayre, R. (2017) Dual signaling evoked by oxidized LDLs in vascular cells. Free Radic Biol Med 106, 118-133

7. Kavurma, M. M., Bhindi, R., Lowe, H. C., Chesterman, C., and Khachigian, L. M. (2005) Vessel wall apoptosis and atherosclerotic plaque instability. J Thromb Haemost 3, 465-472

8. Heermeier, K., Schneider, R., Heinloth, A., Wanner, C., Dimmeler, S., and Galle, J. (1999) Oxidative stress mediates apoptosis induced by oxidized low-density lipoprotein and oxidized lipoprotein(a). Kidney Int 56, 1310-1312

9. Rajendran, P., Rengarajan, T., Thangavel, J., Nishigaki, Y., Sakthisekaran, D., Sethi, G., and Nishigaki, I. (2013) The Vascular Endothelium and Human Diseases. Int J Biol Sci 9, 1057-1069 
10. Pechanova, O., Varga, Z. V., Cebova, M., Giricz, Z., Pacher, P., and Ferdinandy, P. (2015) Cardiac NO signalling in the metabolic syndrome. Br J Pharmacol 172, 1415-1433

11. Muniyappa, R., and Sowers, J. R. (2013) Role of insulin resistance in endothelial dysfunction. Rev Endocr Metab Disord 14, 5-12

12. Mallat, Z., and Tedgui, A. (2000) Apoptosis in the vasculature: mechanisms and functional importance. Br J Pharmacol 130, 947-962

13. Brune, B., von Knethen, A., and Sandau, K. B. (1999) Nitric oxide (NO): an effector of apoptosis. Cell Death Differ 6, 969-975

14. Unoki, H., and Yamagishi, S. (2008) Advanced glycation end products and insulin resistance. Curr Pharm Des 14, 987-989

15. Rother, E., Brandl, R., Baker, D. L., Goyal, P., Gebhard, H., Tigyi, G., and Siess, W. (2003) Subtype-selective antagonists of lysophosphatidic Acid receptors inhibit platelet activation triggered by the lipid core of atherosclerotic plaques. Circulation 108, 741-747

16. Zhang, C., Baker, D. L., Yasuda, S., Makarova, N., Balazs, L., Johnson, L. R., Marathe, G. K., McIntyre, T. M., Xu, Y., Prestwich, G. D., Byun, H. S., Bittman, R., and Tigyi, G. (2004) Lysophosphatidic acid induces neointima formation through PPARgamma activation. $J$ Exp Med 199, $763-774$

17. Tsukahara, T., Tsukahara, R., Yasuda, S., Makarova, N., Valentine, W. J., Allison, P., Yuan, H., Baker, D. L., Li, Z., Bittman, R., Parrill, A., and Tigyi, G. (2006) Different residues mediate recognition of 1-O-oleyllysophosphatidic acid and rosiglitazone in the ligand binding domain of peroxisome proliferator-activated receptor gamma. J Biol Chem 281, 3398-3407

18. Tsukahara, T., Tsukahara, R., Fujiwara, Y., Yue, J., Cheng, Y., Guo, H., Bolen, A., Zhang, C., Balazs, L., Re, F., Du, G., Frohman, M. A., Baker, D. L., Parrill, A. L., Uchiyama, A., Kobayashi, T., Murakami-Murofushi, K., and Tigyi, G. (2010) Phospholipase D2-dependent inhibition of the nuclear hormone receptor PPARgamma by cyclic phosphatidic acid. Mol Cell 39, 421-432 
19. Tsukahara, T., Tsukahara, R., Haniu, H., Matsuda, Y., and Murakami-Murofushi, K. (2015) Cyclic phosphatidic acid inhibits the secretion of vascular endothelial growth factor from diabetic human coronary artery endothelial cells through peroxisome proliferator-activated receptor gamma. Mol Cell Endocrinol 412, 320-329

20. Jude, E. B., Douglas, J. T., Anderson, S. G., Young, M. J., and Boulton, A. J. (2002) Circulating cellular adhesion molecules ICAM-1, VCAM-1, P- and E-selectin in the prediction of cardiovascular disease in diabetes mellitus. Eur J Intern Med 13, 185-189

21. Funk, S. D., Yurdagul, A., Jr., and Orr, A. W. (2012) Hyperglycemia and endothelial dysfunction in atherosclerosis: lessons from type 1 diabetes. Int J Vasc Med 2012, 569654

22. Jarvisalo, M. J., Raitakari, M., Toikka, J. O., Putto-Laurila, A., Rontu, R., Laine, S., Lehtimaki, T., Ronnemaa, T., Viikari, J., and Raitakari, O. T. (2004) Endothelial dysfunction and increased arterial intima-media thickness in children with type 1 diabetes. Circulation 109, 1750-1755

23. Kockx, M. M. (1998) Apoptosis in the atherosclerotic plaque: quantitative and qualitative aspects. Arterioscler Thromb Vasc Biol 18, 1519-1522

24. Cubbon, R. M., Rajwani, A., and Wheatcroft, S. B. (2007) The impact of insulin resistance on endothelial function, progenitor cells and repair. Diab Vasc Dis Res 4, 103-111

25. Hadi, H. A., and Suwaidi, J. A. (2007) Endothelial dysfunction in diabetes mellitus. Vasc Health Risk Manag 3, 853-876

26. Elmore, S. (2007) Apoptosis: a review of programmed cell death. Toxicol Pathol 35, 495-516

27. Pirillo, A., Norata, G. D., and Catapano, A. L. (2013) LOX-1, OxLDL, and atherosclerosis. Mediators Inflamm 2013, 152786

28. Ho, E., Karimi Galougahi, K., Liu, C. C., Bhindi, R., and Figtree, G. A. (2013) Biological markers of oxidative stress: Applications to cardiovascular research and practice. Redox Biol 1, $483-491$

29. Circu, M. L., and Aw, T. Y. (2008) Glutathione and apoptosis. Free Radic Res 42, 689-706 
30. Kvandova, M., Majzunova, M., and Dovinova, I. (2016) The role of PPARgamma in cardiovascular diseases. Physiol Res 65, S343-S363

31. Shibuya, A., Wada, K., Nakajima, A., Saeki, M., Katayama, K., Mayumi, T., Kadowaki, T., Niwa, H., and Kamisaki, Y. (2002) Nitration of PPARgamma inhibits ligand-dependent translocation into the nucleus in a macrophage-like cell line, RAW 264. FEBS Lett 525, 43-47

32. Umemoto, T., and Fujiki, Y. (2012) Ligand-dependent nucleo-cytoplasmic shuttling of peroxisome proliferator-activated receptors, PPARalpha and PPARgamma. Genes Cells 17, $576-596$

33. Calnek, D. S., Mazzella, L., Roser, S., Roman, J., and Hart, C. M. (2003) Peroxisome proliferator-activated receptor gamma ligands increase release of nitric oxide from endothelial cells. Arterioscler Thromb Vasc Biol 23, 52-57

34. Li, D., and Mehta, J. L. (2005) Oxidized LDL, a critical factor in atherogenesis. Cardiovasc Res 68, 353-354

35. Cui, M. Z. (2011) Lysophosphatidic acid effects on atherosclerosis and thrombosis. Clin Lipidol 6, 413-426

36. Chen, M., Masaki, T., and Sawamura, T. (2002) LOX-1, the receptor for oxidized low-density lipoprotein identified from endothelial cells: implications in endothelial dysfunction and atherosclerosis. Pharmacol Ther 95, 89-100

37. Tsukahara, T., Haniu, H., Matsuda, Y., and Murakmi-Murofushi, K. (2016) Short-term treatment with a 2-carba analog of cyclic phosphatidic acid induces lowering of plasma cholesterol levels in ApoE-deficient mice. Biochem Biophys Res Commun 473, 107-113

38. Beckman, J. A., Creager, M. A., and Libby, P. (2002) Diabetes and atherosclerosis: epidemiology, pathophysiology, and management. JAMA 287, 2570-2581

39. Gao, Y., Lu, B., Sun, M. L., Hou, Z. H., Yu, F. F., Cao, H. L., Chen, Y., Yang, Y. J., Jiang, S. L., and Budoff, M. J. (2011) Comparison of atherosclerotic plaque by computed tomography 
angiography in patients with and without diabetes mellitus and with known or suspected coronary artery disease. Am J Cardiol 108, 809-813

40. Sarih, M., Souvannavong, V., and Adam, A. (1993) Nitric oxide synthase induces macrophage death by apoptosis. Biochem Biophys Res Commun 191, 503-508

41. Albina, J. E., Cui, S., Mateo, R. B., and Reichner, J. S. (1993) Nitric oxide-mediated apoptosis in murine peritoneal macrophages. J Immunol 150, 5080-5085

42. Watanabe, N., Miura, S., Zeki, S., and Ishii, H. (2001) Hepatocellular oxidative DNA injury induced by macrophage-derived nitric oxide. Free Radic Biol Med 30, 1019-1028

43. McIntyre, T. M., Pontsler, A. V., Silva, A. R., St Hilaire, A., Xu, Y., Hinshaw, J. C., Zimmerman, G. A., Hama, K., Aoki, J., Arai, H., and Prestwich, G. D. (2003) Identification of an intracellular receptor for lysophosphatidic acid (LPA): LPA is a transcellular PPARgamma agonist. Proc Natl Acad Sci U S A 100, 131-136

44. Cade, W. T. (2008) Diabetes-related microvascular and macrovascular diseases in the physical therapy setting. Phys Ther 88, 1322-1335

45. Elahi, M. M., Kong, Y. X., and Matata, B. M. (2009) Oxidative stress as a mediator of cardiovascular disease. Oxid Med Cell Longev 2, 259-269

46. Basta, G., Schmidt, A. M., and De Caterina, R. (2004) Advanced glycation end products and vascular inflammation: implications for accelerated atherosclerosis in diabetes. Cardiovasc Res 63, 582-592

\section{FIGURE LEGENDS}

\section{Fig. 1.}

eNOS mRNA expression was induced AGP dose- and time-dependent manner in D-HCAECs. (A, B) Cells were treated with the concentration, or for the period indicated. The relative levels of eNOS normalized to $\beta$-actin are expressed as mean \pm SEM $(n=3),{ }^{* *} \mathrm{P}<0.01$. (C) Nitric oxide (NO) production after treatment with or without $10 \mu \mathrm{M}$ AGP for $0,1,3$, and $6 \mathrm{~h}$. (D) Cells were treated with the 
concentration indicated. The production level of NO was determined using the nitric oxide assay kit. NO production was expressed as mean $\pm \mathrm{SEM}(\mathrm{n}=3),{ }^{* *} \mathrm{P}<0.01(0 \mathrm{~h} v s 3 \mathrm{~h}$ and $6 \mathrm{~h}),{ }^{\# \#} \mathrm{P}<0.01(0 \mu \mathrm{M} v s 3 \mu \mathrm{M}$ and $10 \mu \mathrm{M}$ ). eNOS expression was knocked down in D-HCAECs. (E) Real-time PCR measurement of TyrRS mRNA expression in D-HCAEC cells. Relative eNOS levels normalized to glyceraldehyde-3-phosphate dehydrogenase $(G A P D H)$ are expressed as the mean \pm SEM $(\mathrm{n}=3),{ }^{* *} \mathrm{P}<$ 0.01. (F) Total protein was extracted from control siRNA-transfected or eNOS siRNA-transfected cells. Forty-eight hours later, whole-cell lysates were analyzed by western blotting using specific antibodies against eNOS. Incubation with an anti- $\beta$-actin antibody was used as a protein-loading control. (G) The effect of small interfering RNA on eNOS mRNA expression in D-HCAECs. Nitric oxide production after treatment with or without AGP $(10 \mu \mathrm{M})$ for $12 \mathrm{~h}$ was determined using the nitric oxide assay kit.

\section{Fig. 2.}

AGP induces apoptosis in D-HCAECs (A) Stained cells were detected by Hoechst 33342. At least 5 fields of cells per sample were counted and tabulated. Nuclei were stained with Hoechst 33342. Cells were visualized by fluorescence microscopy. Bar indicates $20 \mu \mathrm{m}$. (B) D-HCAEC cells $\left(1 \times 10^{6}\right)$ were treated with AGP $(0,1,3$, and $10 \mu \mathrm{M})$ for $12 \mathrm{~h}$, then harvested and washed twice with ice-cold PBS. Subsequently, the cells were labeled with Annexin V \& Dead Cell Assay kit according to the manufacturer's instructions. Data represent the mean \pm SEM. One-way analysis of variance (ANOVA) was performed to determine the significance $\left({ }^{* *} \mathrm{P}<0.01\right)$. (C) AGP induces the depolarization of the mitochondrial membrane in D-HCAECs. Mitochondrial membrane potential (MMP) was assessed using the Muse Cell Analyzer using the Muse MitoPotential kit as described in Materials and Methods. Data represent the mean \pm SEM of at least 3 independent experiments. One-way analysis of variance (ANOVA) was performed to determine the significance $\left({ }^{* *} \mathrm{P}<0.01\right)$. (D) ROS production in HCAECs and D-HCAECs. ROS production was significantly increased upon treatment with AGP compared with that in HCAECs. Data represent the mean \pm SEM of at least 3 independent experiments. One-way analysis of variance (ANOVA) was performed to determine the significance $\left({ }^{* *} \mathrm{P}<0.01\right)$. (E) $H O-1$ and 
GSS mRNA expression in D-HCAECs and HCAECs after treatment with AGP. Total RNA was extracted from the cells treated with or without AGP $(10 \mu \mathrm{M})$ for $12 \mathrm{~h}$ and the expression level of $\mathrm{HO}-1$ and GSS was determined using quantitative real-time PCR. The relative levels of $\mathrm{HO}-1$ and GSS expression were normalized to GAPDH and are expressed as mean $\pm \mathrm{SEM}(\mathrm{n}=3),{ }^{* *} \mathrm{P}<0.01$.

\section{Fig. 3.}

(A, left) Real-time PCR analysis of HCAECs and D-HCAECs. PPAR 1 and 2 expression levels were normalized to that of GAPDH and are expressed as mean \pm SEM $(\mathrm{n}=3),{ }^{* *} \mathrm{P}<0.01$ (HCAECs $v s$ D-HCAECs). (A, right) Whole cells from D-HCAECs and HCAECs were extracted using RIPA buffer, and PPAR $\gamma$ proteins were separated by SDS-PAGE. The protein levels were compared by visualizing immunoreactive bands by using an enhanced chemiluminescence reagent. Each lane contained $20 \mu \mathrm{g}$ of whole-cell lysate, and $\beta$-actin was used as the loading control. (B) Real-time PCR measurement of PPAR 1 and 2 mRNA expression in D-HCAECs. Cells were treated with $10 \mu \mathrm{M}$ AGP for 0-96 h. PCR was performed by using specific primers for PPAR 1 and $P P A R \gamma 2$. The relative PPAR 1 and $P P A R \gamma 2$ expression levels were normalized to that of GAPDH and are expressed as mean $\pm \operatorname{SEM}(\mathrm{n}=3),{ }^{* *} \mathrm{P}<0.01$. (C) Effects of PPAR $\gamma$ ligands on PPAR $\gamma$ reporter activation and inhibition in HCAECs and D-HCAECs. Cells were transiently transfected with a pGL3-PPRE-acyl-CoA oxidase luciferase reporter vector. The cells were treated with $0.1 \mu \mathrm{M}$ rosiglitazone (Rosi) and AGP $(0.1,1$, and $10 \mu \mathrm{M})$ with or without synthetic PPAR $\gamma$ antagonist GW9662 for 20 h. Luciferase activity was normalized to Renilla luciferase activity. Data are expressed as means $\pm \operatorname{SEM}(\mathrm{n}=4) ;{ }^{* *} \mathrm{P}<0.01$ (Rosi vs Rosi+GW9662), ${ }^{\# \#} \mathrm{P}<0.01$ (AGP $v s$ AGP+GW9662). (D) The immunofluorescence assay for PPAR $\gamma$ nuclear translocation after treatment with $10 \mu \mathrm{M}$ AGP. D-HCAEC cells were immunostained with anti-PPAR $\gamma$ antibody following Alexa Fluor 488-conjugated anti-rabbit IgG (Life Technology, CA, USA). Fluorescence images were acquired using a fluorescence microscope (model BZ-X700; Keyence, Osaka, Japan). The bar indicates $100 \mu \mathrm{m}$. Cell death was analyzed by nuclear staining with Hoechst 33342. (E) D-HCAECs cells were treated with 
$10 \mu \mathrm{M}$ AGP, then the nuclear $(\mathrm{N})$ and cytosolic $(\mathrm{C})$ extracts $(10 \mu \mathrm{g}$ each) were analyzed by western blotting using specific antibodies against PPAR $\gamma$.

\section{Fig. 4.}

(A) AGP induced eNOS mRNA expression and NO production in D-HCAECs was inhibited PPAR $\gamma$ antagonist GW9662 and eNOS inhibitor L-NAME. Data are expressed as means \pm SEM (n=3); left graph, ${ }^{* *} \mathrm{P}<0.01\left(3 \mu \mathrm{M}\right.$ AGP $v s 3 \mu \mathrm{M}$ AGP+ $10 \mu \mathrm{M}$ GW9662), ${ }^{\# \#} \mathrm{P}<0.01(3 \mu \mathrm{M}$ AGP $v s 10 \mu \mathrm{M}$ AGP $+10 \mu \mathrm{M}$ GW9662), right graph, ${ }^{\$} \mathrm{P}<0.01(10 \mu \mathrm{M}$ AGP $v s 10 \mu \mathrm{M}$ AGP + $10 \mathrm{mM}$ L-NAME) (B) The NOS inhibitor, L-NAME, inhibits AGP-induced apoptosis. D-HCAECs were pretreated with L-NAME (10 $\mathrm{mM}$ ) for $60 \mathrm{~min}$ and then subjected to $10 \mu \mathrm{M}$ AGP treatment for $48 \mathrm{~h}$. At least 5 fields of condensed nuclear cells per sample were counted and tabulated. Nuclei were stained with Hoechst 33342. (C) PPAR $\gamma$ antagonist GW9662 restores 2-deoxy-D-glucose (2-DG) incorporation into D-HCAECs, but not in HCAECs. Cells were treated with indicated compounds in the presence of 2-DG for $24 \mathrm{~h}$, followed by measurement of the incorporated 2-DG using the assay kit. Data are presented as the mean \pm SEM (n=3). ${ }^{* *} \mathrm{P}<0.01$ (Insulin $v s 10 \mu \mathrm{M}$ AGP + insulin), ${ }^{\# \#} \mathrm{P}<0.01(10 \mu \mathrm{M}$ AGP + insulin $v s 10 \mu \mathrm{M}$ AGP + $10 \mu \mathrm{M}$ GW9662 + insulin). (D) Effect of $10 \mu \mathrm{M}$ AGP on AGEs formation. AGEs were detected with OxiSelect $^{\mathrm{TM}}$ AGE ELISA kit. D-HCAECs were incubated in AGP plus $10 \mu \mathrm{M}$ carbonyl cyanide m-chlorophenylhydrazone $(\mathrm{CCCP})$ for $72 \mathrm{~h}$. Data are presented as the mean $\pm \mathrm{SEM}(\mathrm{n}=3) .{ }^{* *} \mathrm{P}<0.01(10$ $\mu \mathrm{M}$ AGP $v s 10 \mu \mathrm{M}$ AGP+GW9662), ${ }^{\#} \mathrm{P}<0.01(10 \mu \mathrm{M}$ AGP $v s 10 \mu \mathrm{M}$ AGP + 10 $\mu$ M CCCP).

\section{Fig. 5.}

(A) D-HCAECs were incubated with indicated concentrations $(0,3,10,30,50$, and $100 \mu \mathrm{g} / \mathrm{ml})$ of ox-LDL (left) or nLDL (right) for $24 \mathrm{~h}$ at $37^{\circ} \mathrm{C}$. The expression level of LOX-1 (upper panel) and CD36 (lower panel) was determined by using quantitative real-time PCR. The relative levels of LOX-1 and CD36 normalized to GAPDH are expressed as mean \pm SEM $(\mathrm{n}=3),{ }^{* *} \mathrm{P}<0.01$. (B) D-HCAECs were incubated with AGP, GW9662 or AGP plus GW9662 for $24 \mathrm{~h}$ at $37^{\circ} \mathrm{C}$. The expression level of $L O X-1$ 
and $C D 36$ was determined by using quantitative real-time PCR. The relative levels of $L O X-1$ and $C D 36$ normalized to that of GAPDH are expressed as mean \pm SEM $(n=3),{ }^{* *} \mathrm{P}<0.01(\mathrm{C})$ Effects of ox-LDL on PPAR $\gamma$ reporter activation in D-HCAECs. Cells were transiently transfected with a pGL3-PPRE-acyl-CoA oxidase luciferase reporter vector. The cells were treated with ox-LDL with or without GW9662 for $24 \mathrm{~h}$ at $37^{\circ} \mathrm{C}$. Luciferase activity was normalized to $\beta$-galactosidase. Data are expressed as means $\pm \operatorname{SEM}(\mathrm{n}=3) ;{ }^{* *} \mathrm{P}<0.01(0$ vs $10,30,50$, and $100 \mu \mathrm{M}$ ox-LDL $) .{ }^{\# \#} \mathrm{P}<0.01(50 \mu \mathrm{M}$ ox-LDL $v s 50 \mu \mathrm{M}$ ox-LDL+ $10 \mu \mathrm{M}$ GW9662). (D) Uptake of DiI-ox-LDL by AGP-treated D-HCAECs. D-HCAECs were treated with $10 \mu \mathrm{M}$ AGP for $24 \mathrm{~h}$ in the absence or presence of anti-LOX-1 antibody. After that incubated with 5 or $50 \mu \mathrm{g} / \mathrm{ml}$ DiI-ox-LDL for $2 \mathrm{~h}$. Fluorescence images were acquired using a fluorescence microscope (Left images). Graph shows a quantitative analysis of the images. Data are expressed as mean \pm SEM $(n=3),{ }^{* *} \mathrm{P}<0.01$. (E) ox-LDL-mediated induction of the expression of cytokine/chemokine mRNA was confirmed by real-time PCR. D-HCAECs were exposed to $10 \mu \mathrm{M}$ AGP for $24 \mathrm{~h}$, then incubated with $50 \mu \mathrm{g} / \mathrm{ml}$ DiI-ox-LDL for $2 \mathrm{~h}$. The mRNA levels of cytokine/chemokine were determined. The relative levels of cytokine/chemokine normalized to $G A P D H$ are expressed as mean $\pm \operatorname{SEM}(\mathrm{n}=3),{ }^{* *} \mathrm{P}<0.01$.

\section{Fig. 6.}

Apolipoprotein E knockout mice (apoE-/-) showed increased AGP levels. The ApoE-/-+ 2ccPA group was administered 2ccPA by intraperitoneal injection, while the control group (ApoE-/- group) was administered an equal volume of PBS for 4 weeks. (A) The extracts of each sample were analyzed using LC-MS/MS to confirm AGP16:0, 18:0, and 18:1 levels. The right graph is a graphical representation of the three most abundant AGP in apoE-/- mice fed a normal-fat diet (ND) or high-fat diet (HFD). Data are expressed as means $\pm \mathrm{SEM}(\mathrm{n}=3) ;{ }^{* *} \mathrm{P}<0.01$ (ND $v s$ HFD). ${ }^{\# \#} \mathrm{P}<0.01$ (HFD vs HFD+2ccPA). (B) The development of aortic atherosclerotic lesion in apoE-/- mice maintained on a ND, HFD, and HFD+2ccPA for 4 weeks (left). Quantification of total aorta atherosclerotic burden (indicated by an arrow) after 4 weeks of treatment (right). Data are expressed as means $\pm \operatorname{SEM}(\mathrm{n}=3) ;{ }^{* *} \mathrm{P}<0.01(\mathrm{ND} v s$ 
HFD). ${ }^{\#} \mathrm{P}<0.01$ (HFD vs HFD+2ccPA). (C) Real-time PCR shows inhibition of AGP associated genes (eNOS, LOX-1, CD36, and $I L-6$ ) expression by 2ccPA in ApoE-/- mice. The relative levels of genes normalized to $G A P D H$ are expressed as mean \pm SEM $(\mathrm{n}=3),{ }^{* *} \mathrm{P}<0.01$ (HFD vs HFD+2ccPA).

\section{Fig.7.}

A summary of AGP proatherosclerotic effects mediated by LOX-1 and CD36 in D-HCAECs. AGP activates PPAR $\gamma$ and promotes downstream signaling. AGP regulates PPAR $\gamma$ function required for vascular wall pathologies, including proinflammatory activation, apoptosis, endothelial dysfunction (NO, AGEs), and ox-LDL uptake. 
A

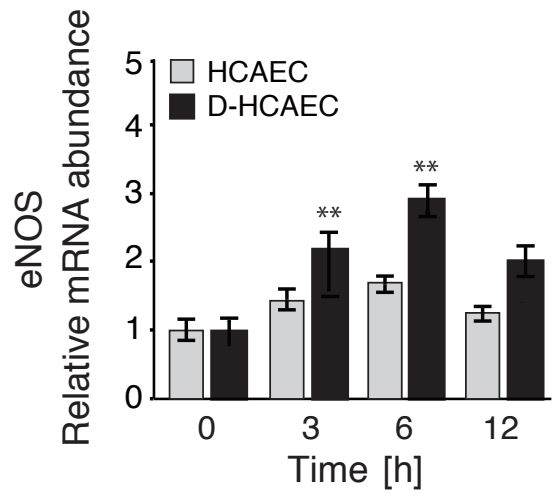

C

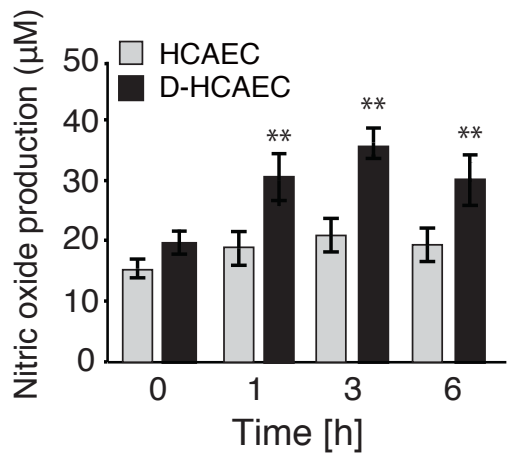

$E$

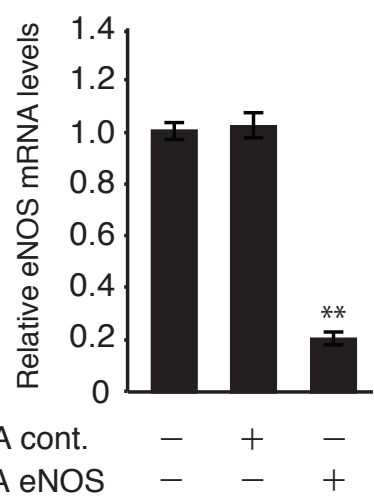

G

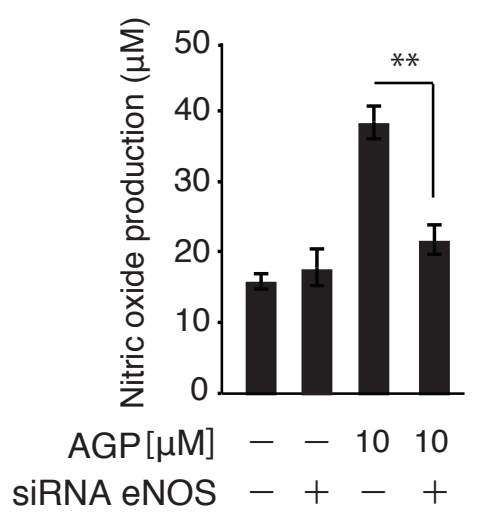

siRNA cont. SiRNA ENOS - -+
B

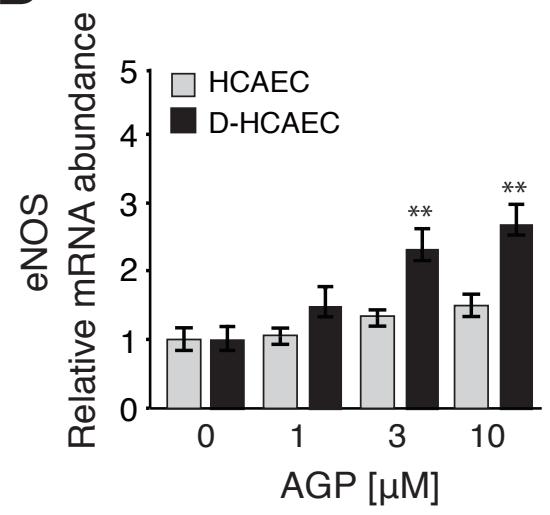

D

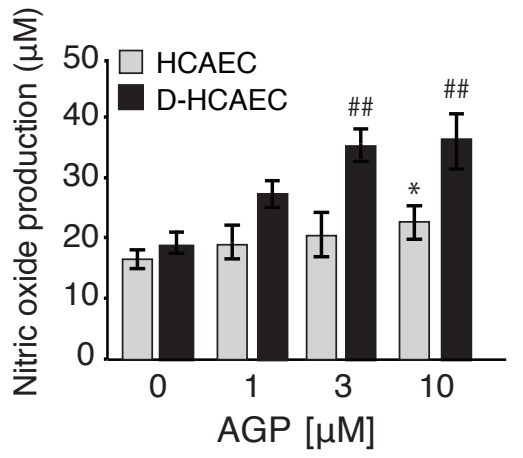

F

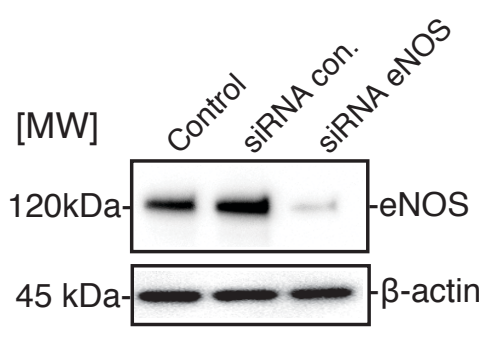

Fig.1 
A
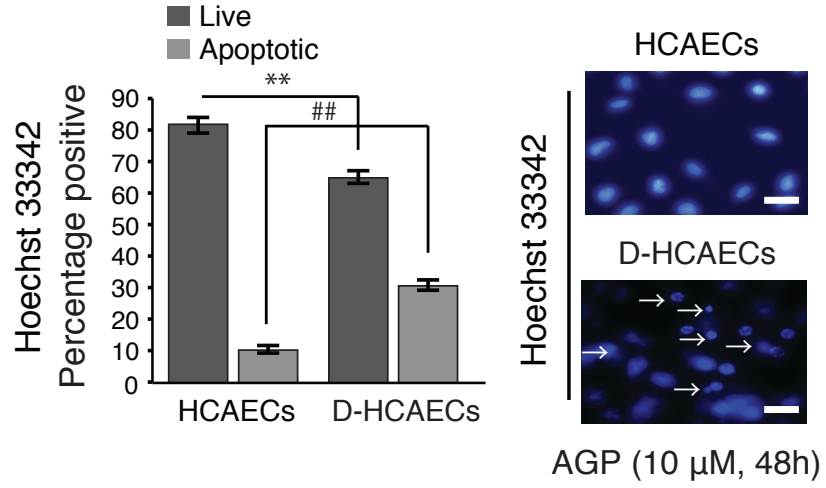

B

C

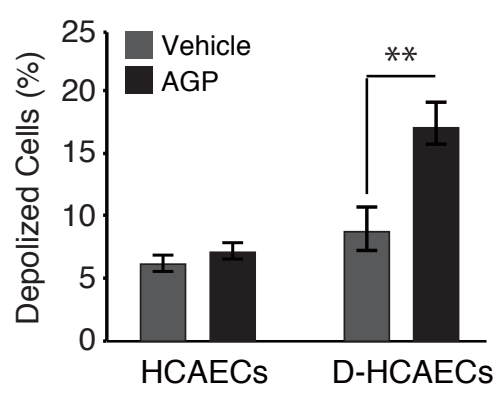

E

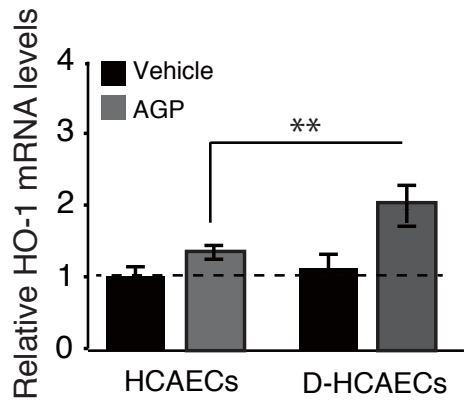

D

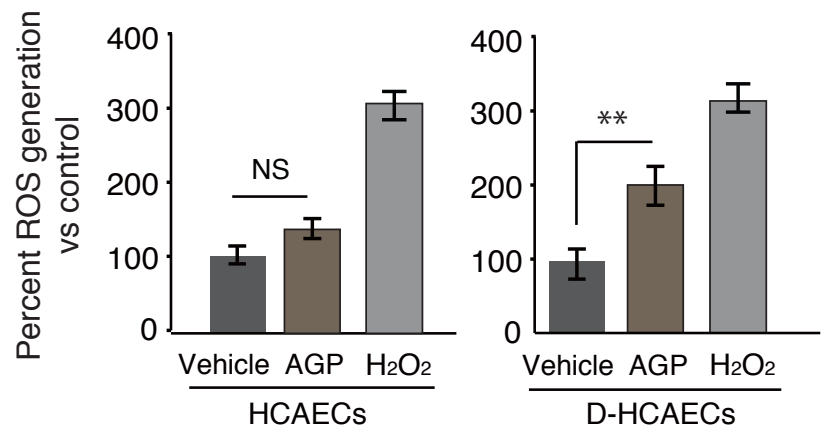

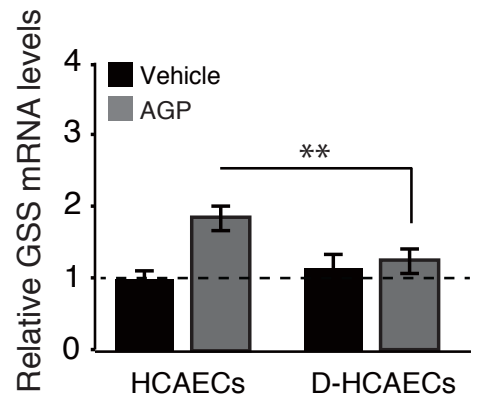

Fig.2 
A

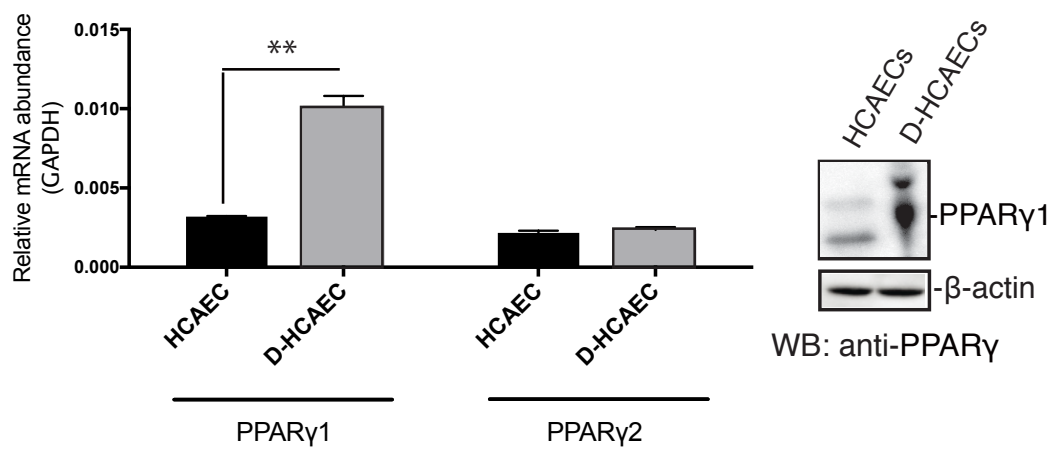

B

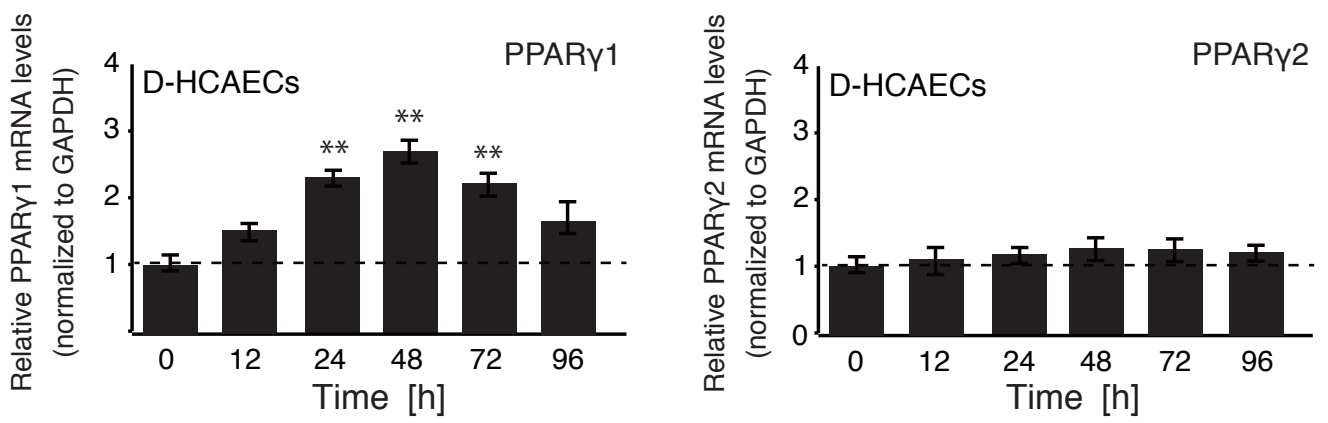

C

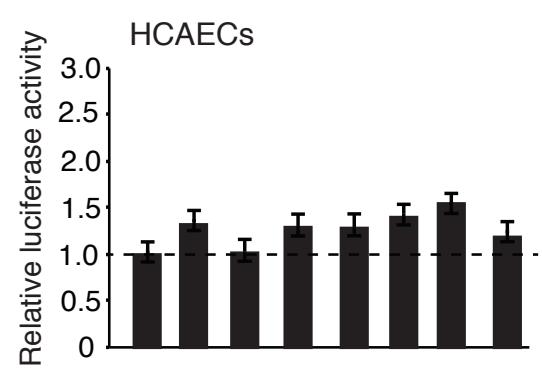

$\mathrm{AGP}[\mu \mathrm{M}]-\quad-\quad-0.111010$

Rosi $[\mu \mathrm{M}]-0.1-0.1-\cdots-$

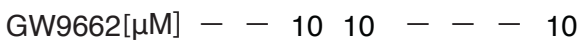

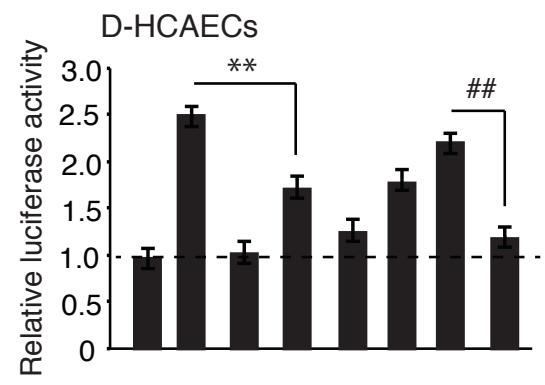

AGP $[\mu \mathrm{M}]--\cdots 0.111010$

Rosi $[\mu \mathrm{M}]-0.1-0.1---$

GW9662 $[\mu \mathrm{M}]--1010-\ldots 10$

D

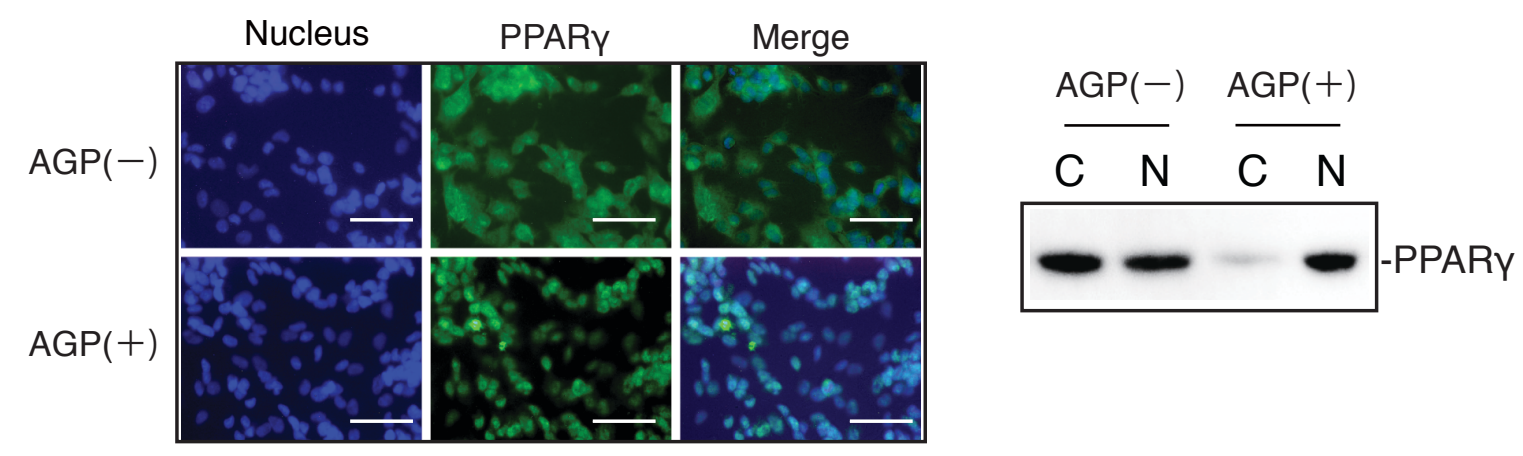

Fig.3 
A
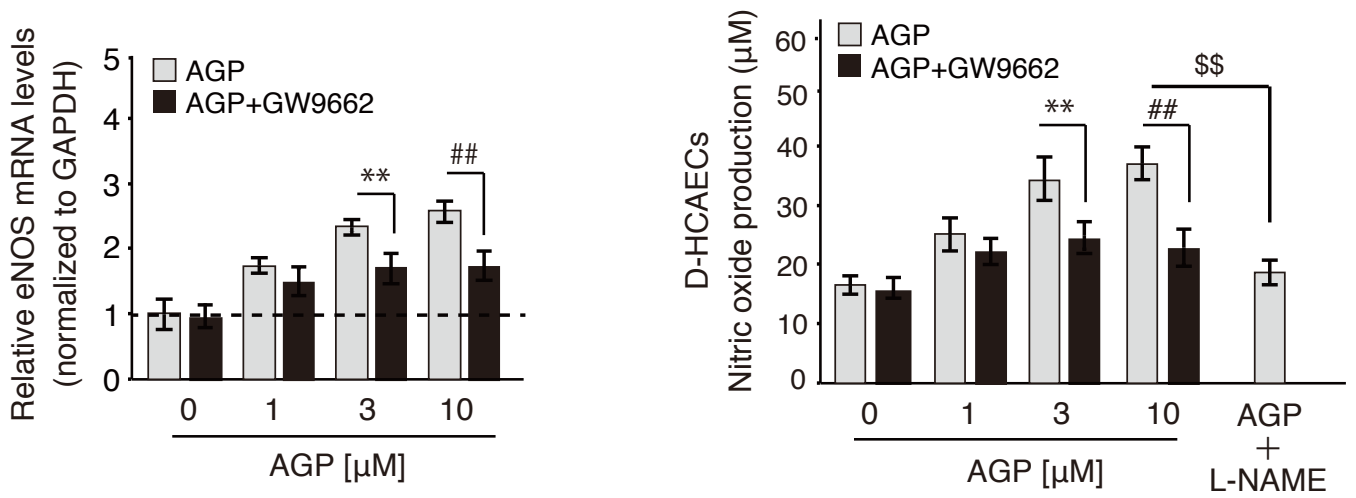

B

C
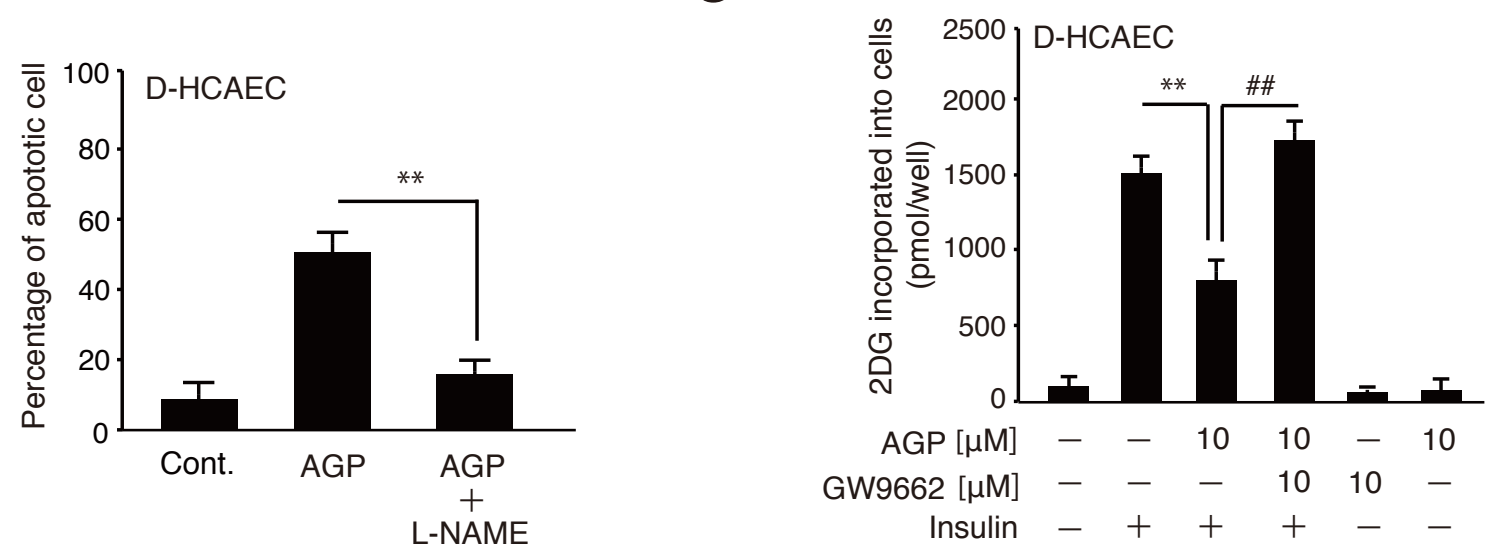

D

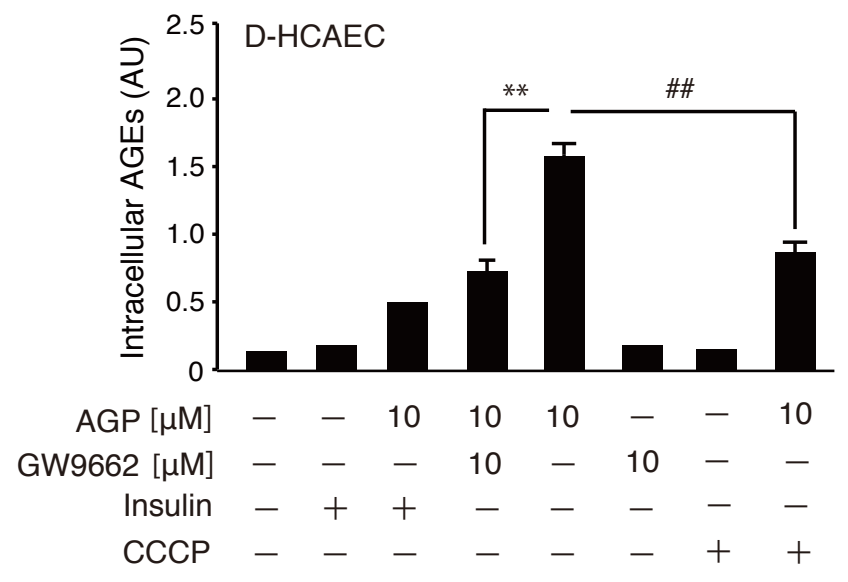


A
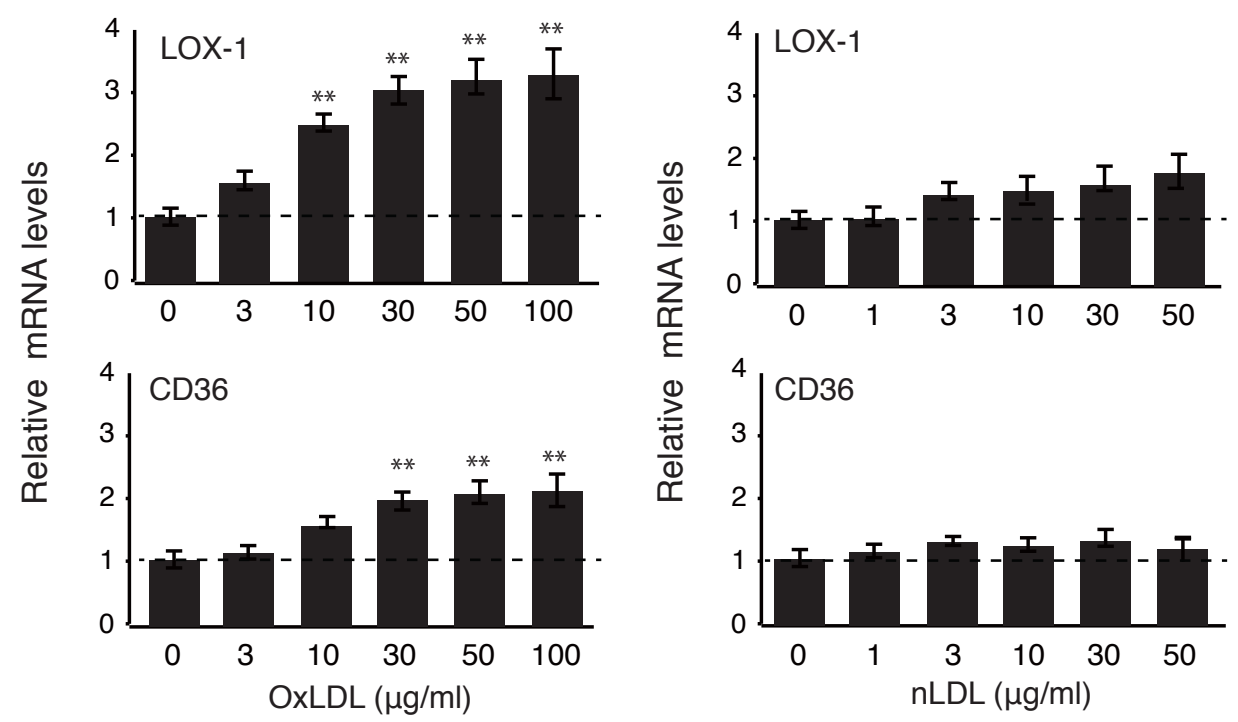

B
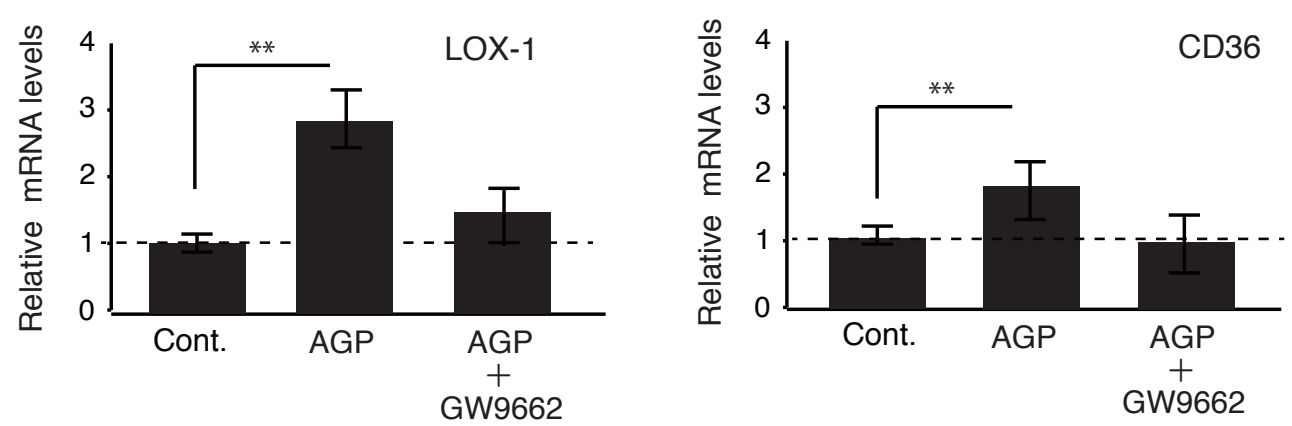

C

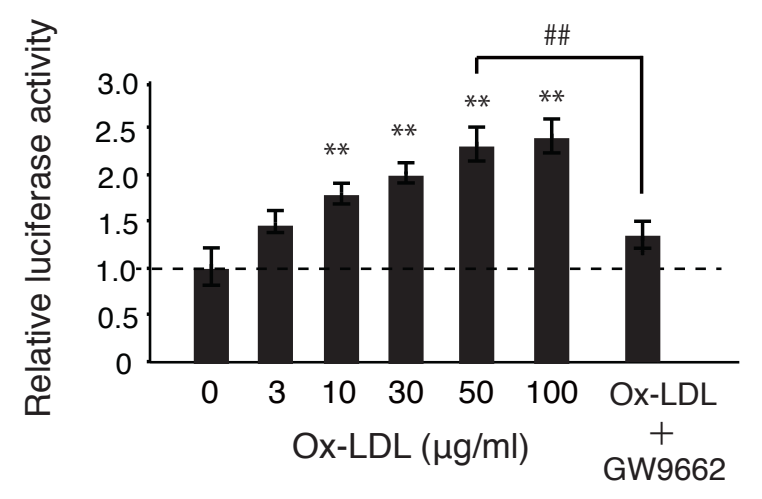

E

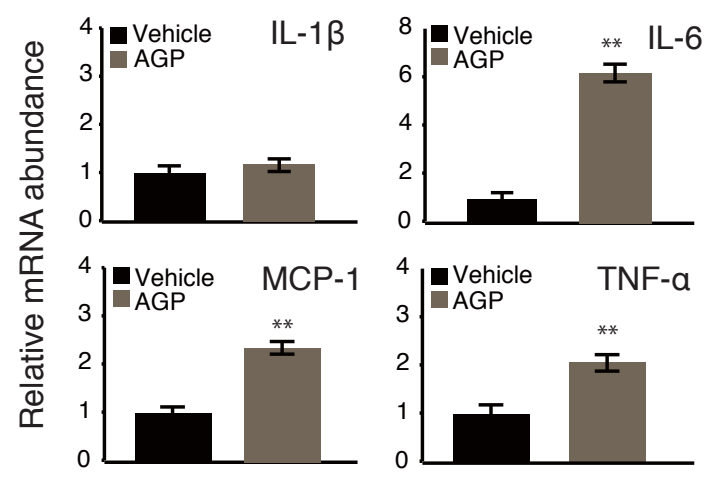

D

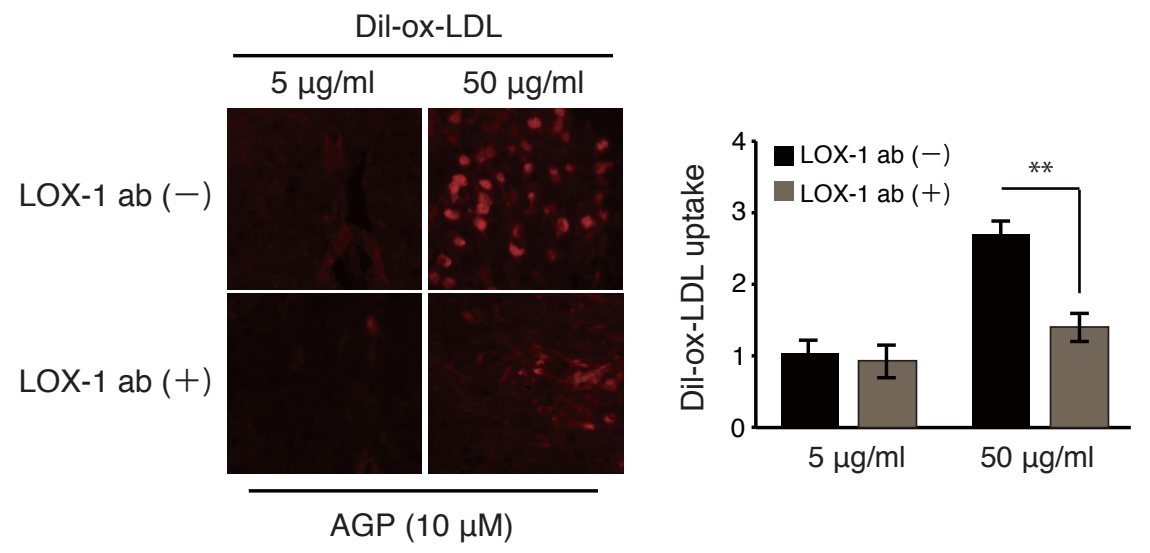

Fig.5 
A
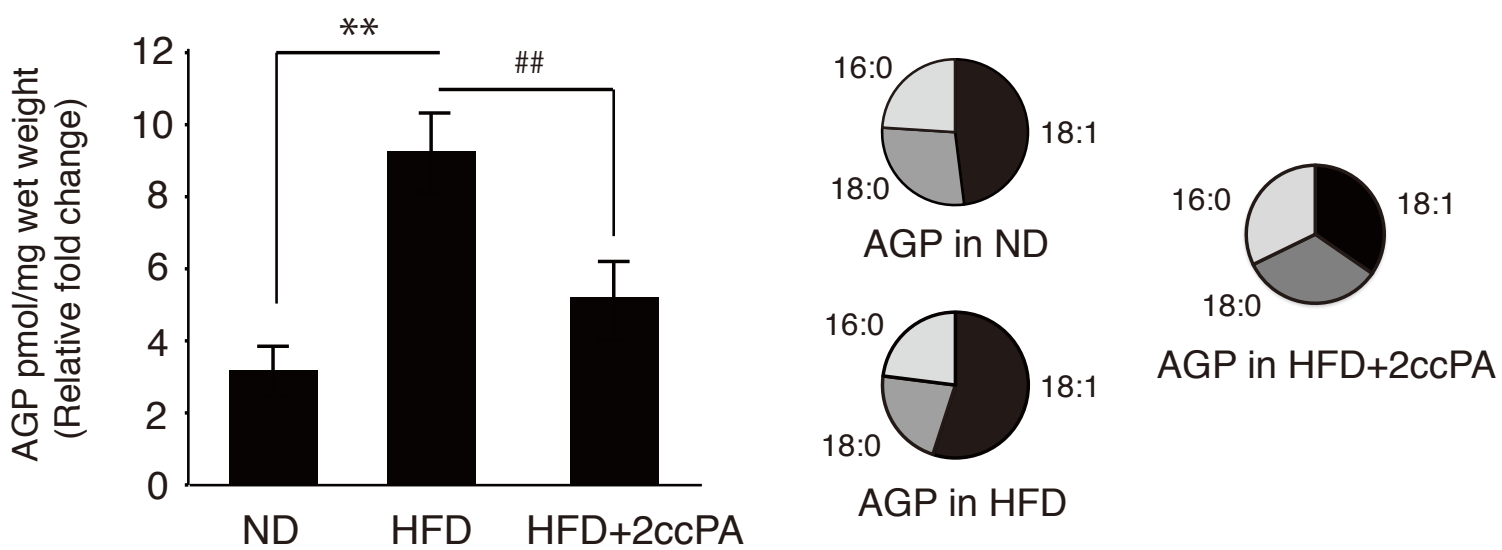

B
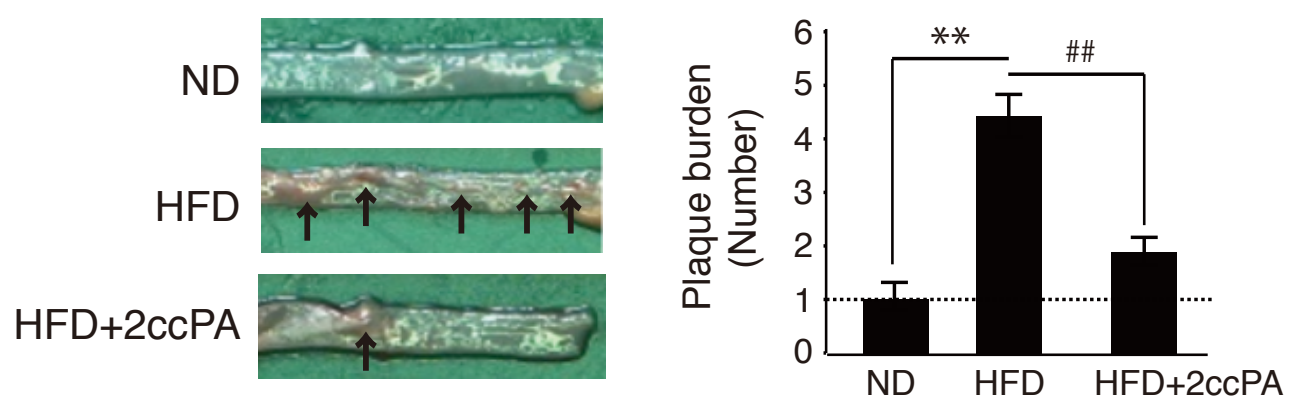

C
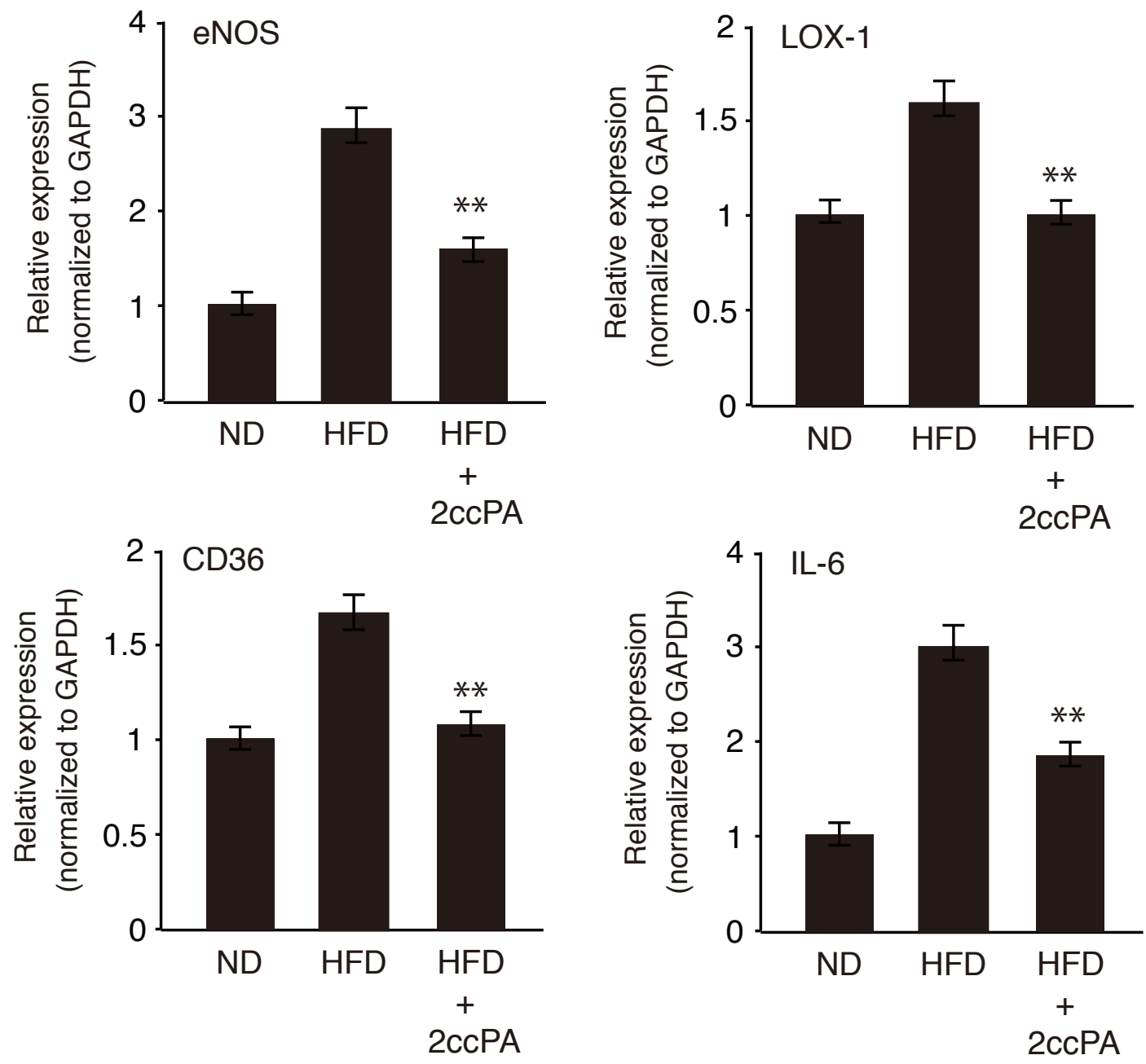

Fig.6 


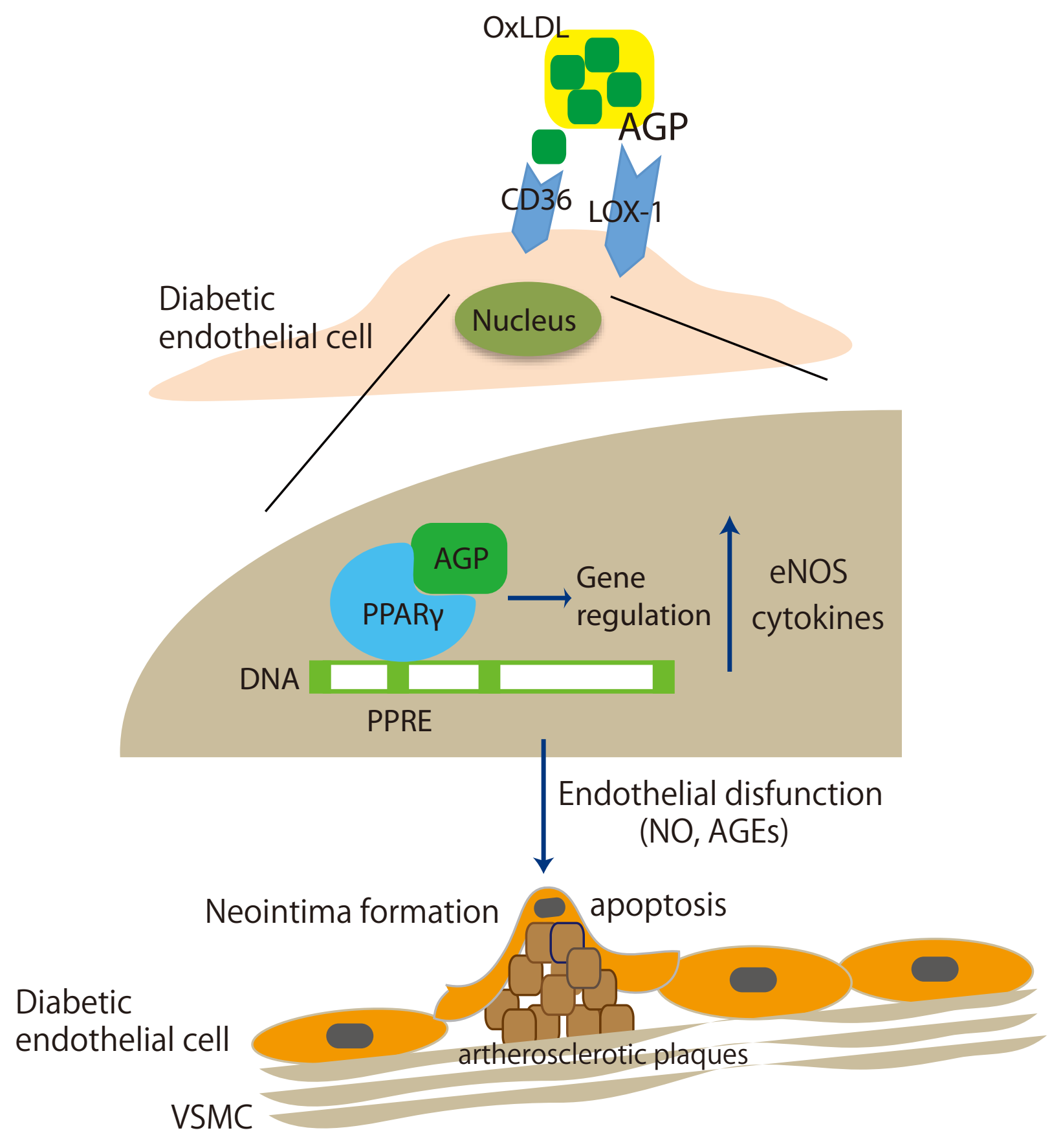

Fig.7 
Supplementary Material
Click here to download Supplementary Material: Supplementary data.docx

Supplementary Material
Click here to download Supplementary Material: Supplementary data.docx

Click here to download Supplementary Material: Supplementary data.docx

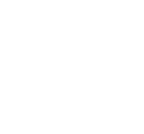

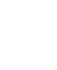

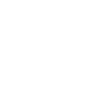

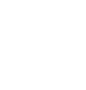
(1) (1) (1) $\sqrt{3}$ (1) (1) (1) . . . . . . . . . . . . . . . . . 